\title{
Changes in the variability of global land precipitation
}

\author{
Fubao Sun, ${ }^{1,2}$ Michael L. Roderick, ${ }^{1,2,3}$ and Graham D. Farquhar ${ }^{1,2}$ \\ Received 30 July 2012; revised 24 August 2012; accepted 27 August 2012; published 2 October 2012.
}

[1] In our warming climate there is a general expectation that the variability of precipitation $(P)$ will increase at daily, monthly and inter-annual timescales. Here we analyse observations of monthly $P(1940-2009)$ over the global land surface using a new theoretical framework that can distinguish changes in global $P$ variance between space and time. We report a near-zero temporal trend in global mean $P$. Unexpectedly we found a reduction in global land $P$ variance over space and time that was due to a redistribution, where, on average, the dry became wetter while wet became drier. Changes in the $P$ variance were not related to variations in temperature. Instead, the largest changes in $P$ variance were generally found in regions having the largest aerosol emissions. Our results combined with recent modelling studies lead us to speculate that aerosol loading has played a key role in changing the variability of $P$. Citation: Sun, F., M. L. Roderick, and G. D. Farquhar (2012), Changes in the variability of global land precipitation, Geophys. Res. Lett., 39, L19402, doi:10.1029/2012GL053369.

\section{Introduction}

[2] In many instances, e.g., agricultural and natural ecosystems, and for water resources planning, changes in the variability (or upper/lower extremes) of precipitation $(P)$ (e.g., floods and droughts) over the land surface can be as important as changes in the mean [Easterling et al., 2000a, 2000b; Rodríguez-Iturbe and Porporato, 2004; Porporato et al., 2004]. With global warming, climate models project increased $P$ variability in most regions at daily [O'Gorman and Schneider, 2009], monthly [Benestad, 2006] and interannual [Boer, 2009; Held and Soden, 2006; Rind et al., 1989; Wetherald, 2010] timescales. Expectations are for $P$ extremes in storm events to increase with the saturation vapour pressure in the atmosphere $\left(\sim 7 \% \mathrm{~K}^{-1}\right)$ [Trenberth et al., 2003]. Energetic constraints limit the increase of global $P\left(\sim 2 \% \mathrm{~K}^{-1}\right)$ [Allen and Ingram, 2002] so that the mean time interval between successive storms is also expected to increase [Trenberth et al., 2003] by $\sim 5 \% \mathrm{~K}^{-1}$. An increase in $P$ extremes in storm events due to warming is relevant over short time scales (minutes-hours) and relates directly to the occurrence of floods [Allan and Soden, 2008;

\footnotetext{
${ }^{1}$ Research School of Biology, Australian National University, Canberra, ACT, Australia.

${ }^{2}$ Australian Research Council Centre of Excellence for Climate System Science, Sydney, New South Wales, Australia.

${ }^{3}$ Research School of Earth Sciences, Australian National University, Canberra, ACT, Australia.

Corresponding author: M. L. Roderick, Research School of Biology, Australian National University, Canberra, ACT 0200, Australia. (michael.roderick@anu.edu.au)

C2012. American Geophysical Union. All Rights Reserved. 0094-8276/12/2012GL053369
}

O'Gorman and Schneider, 2009]. However, care is needed before applying that logic to the longer periods (monthsyears) of relevance to droughts since relative changes in the dry period length would be small. For example, Chicago's mean annual $P(910 \mathrm{~mm})$ falls in $\sim 660$ hours leaving dry the remaining 8100 hours [Eagleson, 2002]. If it fell in 5\% less time the dry period length would increase by $\sim 0.4 \%$ $(=0.05 \times 660 / 8100)$. Even halving the total duration of storms and thereby doubling the average storm intensity would still only increase the dry period by $4 \%$. Hence, a change in the total storm duration does not provide guidance on changes in longer term $P$ variability on time scales relevant to droughts.

[3] Long-term spatial databases at monthly resolution are available to evaluate changes in $P$ variability on timescales relevant to droughts. In terms of generic expectations we note that $P$ cannot be less than zero and the simplest model is for local-scale variability in $P$ to increase (decrease) with increases (decreases) in the local-scale mean $P$ [Groisman et al., 1999; Rind et al., 1989]. Observations over the past 50 years show little variation in global mean $P$ [Huffman et al., 2009] for periods longer than the turnover time of water in the atmosphere ( $\sim 10$ days). Hence, over monthly (and longer timescales), any increase in $P$ in a given region must have been roughly balanced by decreases elsewhere such that the global $P$ remained near constant. Thus, when expressed in terms of precipitation the "wet get wetter and dry get drier" idea [Chou et al., 2007; Trenberth, 2011; Held and Soden 2006] can be interpreted to imply an increase in the temporal variance in wet regions (since $P$ is supposed to increase there) coupled with a decrease in dry regions (since $P$ is supposed to decrease there) that could balance leaving little overall temporal change in $P$ variability. However, such local changes also require a redistribution of $P$ and in the wet-get-wetter dry-get-drier scenario there would also be an accompanying increase in the spatial variance. The key point is that any analysis technique that only examines the changes over time at individual grid-boxes will ignore this spatial component and therefore ignore a potentially important change in the overall climate.

[4] Inspired by the analysis of variance method [von Storch and Zwiers, 1999; Wilks, 2011], we recently developed a general approach that partitions the overall variance, called the grand variance, into separate spatial and temporal components [Sun et al., 2010]. This new approach can be applied to any space-time database and does not require assumptions about the independence of the data. (See the mathematical derivation in Sun et al. [2010].) Here we use the same gridded databases that are already in widespread use. For each decade, we first lump space and time to form one empirical distribution and calculate the grand variance. Following that we separately calculate the temporal variance of each grid-box and also calculate the spatial variance across all grid-boxes. The innovation is that the method 
describes how the separate spatial and temporal components are added to equal the grand variance. This new procedure has the advantage that the sources of variation, whether through space, or through time, can be disentangled [Sun et al., 2010]. Here we use that technique to examine changes in $P$ variability in long-term monthly observations.

[5] Data on oceanic $P$ are currently only available from 1979 [Huffman et al., 2009; Xie and Arkin, 1997] with many unresolved issues in their use for trend analysis [Yin et al., 2004] (see Section S1 in Text S1 in the auxiliary material). ${ }^{1}$ However, the critical impacts of changes in $P$ variability (agriculture, water resources) occur over land. We use global land-based $\left(2.5^{\circ} \times 2.5^{\circ}\right)$ observations in seven monthly databases: GPCC(1901-2009) [Rudolf and Schneider, 2005], CRU(1901-2006) [Mitchell and Jones, 2005], GPCP(1979-2008) [Huffman et al., 2009], CMAP (1979-2008) [Xie and Arkin, 1997], the database compiled by Dai et al. [1997] (1920-1995), GHCN (1940-2009, $\left.5^{\circ} \times 5^{\circ}\right)$ [Peterson and Vose, 1997], and VASClimO [Rudolf and Schneider, 2005] (1951-2000) (see Section S1.1 in Text S1). The VASClimO database used a mostly fixed number of $P$ measurement stations over time [Rudolf and Schneider, 2005] (Figure S6a in Text S1) and we adopted that as a reference. To further minimise interpolation problems (see Section S1.3 in Text S1) we use the GPCC metadata to define a spatial mask (fixed over the entire period, Figure S6b in Text S1) by those grid-boxes having at least one measurement site for $90 \%$ of the months over the $1951-$ 2000 (VASClimO) period. We also tested other spatial masks using more stringent criteria but the same conclusions held (see Figures S6 and S7 in Text S1). The final mask includes 1,987 grid-boxes ( $\sim 69 \%$ of global land area excl. Antarctica) and was used to calculate the grand mean $\left(\mu_{\mathrm{g}}\right)$ and grand variance $\left(\sigma_{\mathrm{g}}^{2}\right)$ for each successive decade for all seven databases. The different databases gave nearly identical results for the period 1940-2009 (Figures S7-S11 in Text S1). All subsequent results use the mask derived from the GPCC observations (1940-2009).

\section{Results}

[6] We find that $\mu_{\mathrm{g}}$ has a near-zero trend (Figure 1a) while $\sigma_{\mathrm{g}}^{2}$ has a decline of $\sim 6 \%(1940-1999, p=0.003$, MannKendall Test) before an increase of $\sim 5 \%$ in the final decade (2000-2009) giving an overall decline (Figure 1b). The 99 Percentile $\left(P_{0.99}\right.$, Figure 1c), calculated from the empirical distribution lumping space and time [Allan and Soden, 2008; Allen and Ingram, 2002; O'Gorman and Schneider, 2009; Sugiyama et al., 2010], tracks $\sigma_{\mathrm{g}}^{2}$. Note that the trends in $\sigma_{\mathrm{g}}^{2}$ do not follow those of temperature (Figure 1b). To examine the trends in detail we decompose $\sigma_{\mathrm{g}}^{2}$ into separate spatial and temporal components following Sun et al. [2010] (Section S1.4 in Text S1). The (linear) trend in $\sigma_{\mathrm{g}}^{2}$ over the 7 decades (1940-2009) is $-34.4\left(\mathrm{~mm} \mathrm{month}^{-1}\right)^{2}$ decade $^{-1}$ with $1 / 3$ due to a decline in the spatial component $(-11.9)$ and $2 / 3$ due to the temporal component $(-22.8)$ (Table S2 in Text S1). Further, the decline in the temporal component of $\sigma_{\mathrm{g}}^{2}$ is almost entirely due to a decline in the intra-annual component (i.e., seasonal cycle, Figure S13d in Text S1) with only a small residual change in the inter-annual

\footnotetext{
${ }^{1}$ Auxiliary materials are available in the HTML. doi:10.1029/ 2012 GL053369.
}

component (Figure S13e in Text S1). The decrease in intraannual variance could seem counter to an earlier report that the difference between wet and dry season precipitation has increased in the tropics for 1979-2005 [Chou et al., 2007]. Over that shorter period we also find an increase in the intraannual component (Figures S12b and S13b and Table S4 in Text S1). However, over the full 1940-2009 period, the overall trend in $\sigma_{\mathrm{g}}^{2}$ remains one of decline (Figure $1 \mathrm{~b}$ and Table S2 in Text S1). The trend in the temporal component of $\sigma_{\mathrm{g}}^{2}$ shows a complex spatial pattern of change (Figure 1e) and regions with increasing mean $P$ (Figure 1d) tend to show increasing $P$ variance (Figure 1e) and vice-versa (Figure $\mathrm{S} 14$ in Text S1). However, that simple relation does not adequately explain the overall global result because $\sigma_{\mathrm{g}}^{2}$ decreases whilst $\mu_{\mathrm{g}}$ has a near-zero trend (Figures $1 \mathrm{a}$ and $1 \mathrm{~b}$ and Table S2 in Text S1).

[7] The unexpected results prompt the question - what has changed in the $P$ frequency distribution? To address that we develop a generalised space-time probability distribution for $P$ that is related to the sequence of wet and zero- $P$ months. In the monthly (gridded) observations, $P$ rarely equals zero, although it can be close. We define the zero- $P$ using a threshold, $P_{0}$. When $P>P_{0}$ the month is classified as wet, and the wet month frequency $\left(f_{w}(P)\right)$ follows the gamma distribution [Eagleson, 2002; Groisman et al., 1999; Karl et al., 1995; Rodríguez-Iturbe and Porporato, 2004; Thom, 1958; Tsonis, 1996; Porporato et al. 2004]

$$
f_{w}(P)=P^{\alpha-1} \frac{\exp (-P / \beta)}{\Gamma(\alpha) \beta^{\alpha}}, \quad \text { for } P>P_{0}
$$

with $\alpha$ the shape parameter controlling the relative contribution from light versus heavy $P$ (Figure S15a in Text S1), $\Gamma(\alpha)$ the factorial gamma function and $\beta\left(\mathrm{mm} \mathrm{month}^{-1}\right)$ the scale parameter that mostly controls the frequency at the upper $P$ extremes (Figure S15b in Text S1). For zero- $P$ months we use the uniform distribution, $f_{d}(P)=\frac{1}{P_{0}}$, for $0 \leq P \leq P_{0}$. The mixture distribution is defined by $f(P)=(1-w)$ $f_{d}(P)+w f_{w}(P)$ (see Section S2.1 in Text S1), where $w$ (range $0-1$ ) is the number of wet months expressed as a fraction of the total number of months. The mean and variance of the mixture distribution are $\mu=(1-w) \mu_{d}+w \mu_{w}$ and $\sigma^{2}=(1-w) \sigma_{d}^{2}+w \sigma_{w}^{2}+w(1-w)\left(\mu_{w}-\mu_{d}\right)^{2}$ respectively [Wilks, 2011]. When combined with the definition (equation (1)), the grand mean is

$$
\mu_{g}=(1-w) \frac{P_{0}}{2}+w \alpha \beta \approx w \alpha \beta
$$

and the grand variance is

$$
\begin{aligned}
\sigma_{g}^{2} & =(1-w) \frac{P_{0}^{2}}{12}+w \alpha \beta^{2}+w(1-w)\left(\alpha \beta-\frac{P_{0}}{2}\right)^{2} \\
& \approx w \alpha \beta^{2}(1+\alpha-w \alpha)
\end{aligned}
$$

The approximations in equation (2) arise since $P_{0}$ is close to, but not exactly, zero. We derived distributions by systematically varying the threshold $P_{0}$ between 1 to $2 \mathrm{~mm} \mathrm{month}^{-1}$. In all cases, the results were nearly identical and we set the threshold $P_{0}$ to be $1 \mathrm{~mm}$ month $^{-1}$ (see Section S2.3 in Text S1). The observations follow the mixture distribution (Figure 2 and Figures S16 and S17 in Text S1). 

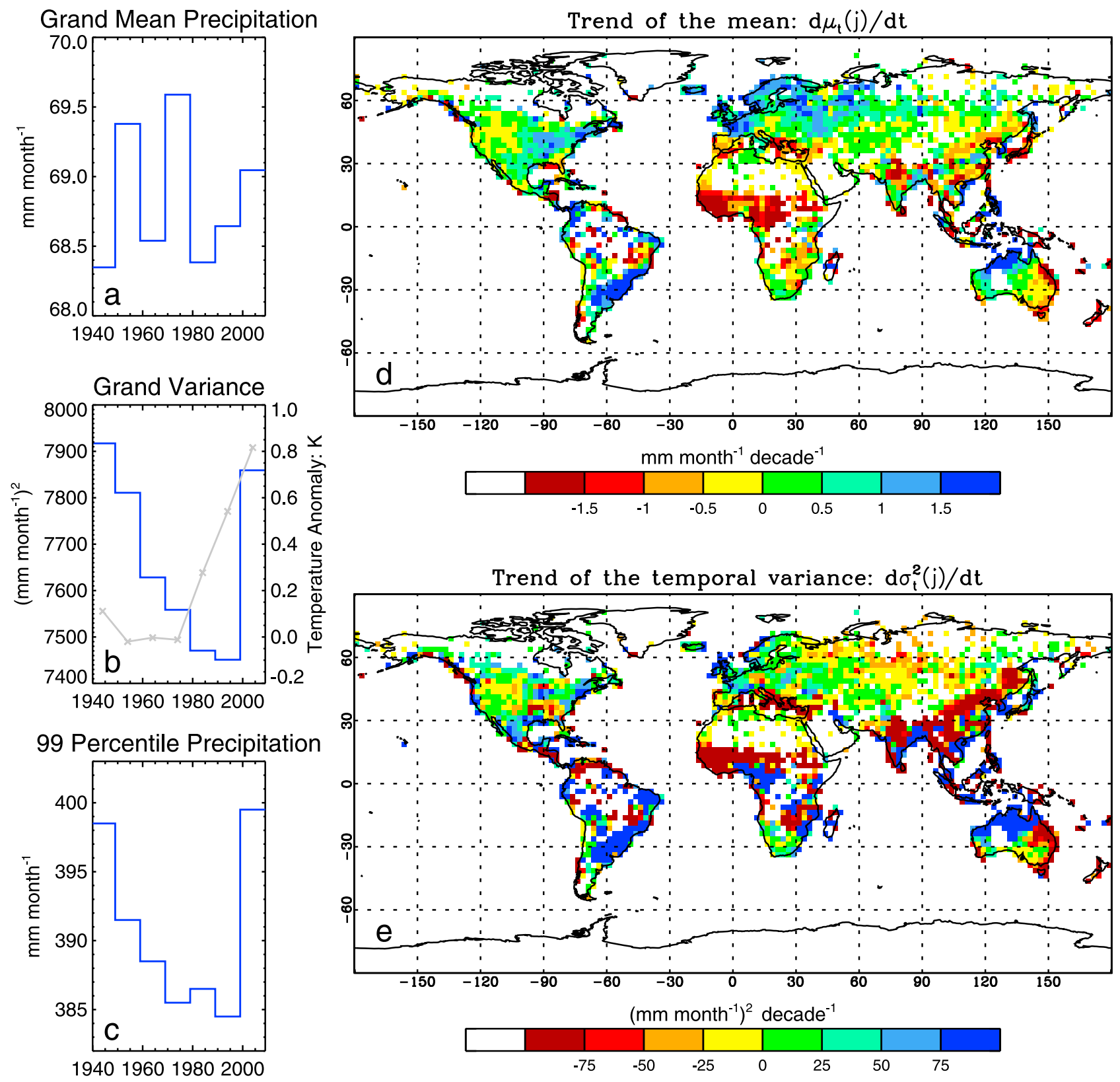

Figure 1. Trends in $P$ variability. Time series of the decadal (a) grand mean $\left(\mu_{\mathrm{g}}\right)$, (b) grand variance $\left(\sigma_{\mathrm{g}}^{2}\right.$, blue line) (with temperature anomaly (grey line) from the GISS database [Hansen et al., 2010]), and (c) the 99 percentile of monthly precipitation (GPCC, 1940-2009, with the land mask); and spatial pattern of trends in the (d) mean and (e) temporal variance.

[8] For detection purposes we derive differentials (per equation (2)) for changes in the distribution over successive decades (equations (S6)-(S9) and Section S2.2 in Text S1). First, there is little change in $w$ (Figure 3a). Second, because of the near zero-trend in both $w$ and $\mu_{g}$ (Figure $3 b$ ), the observed increase in $\alpha$ must be balanced by an equal and opposite relative decrease in $\beta$ (Figures $3 \mathrm{a}$ and $3 \mathrm{~b}$ ). $\sigma_{g}^{2}$ is twice as sensitive to the same relative change in $\beta$ compared to $\alpha$ (equation (S9) in Text $\mathrm{S} 1$ ) and therefore declines (Figure 3c).

[9] The results (Figure 3a) imply a redistribution where $P$ is taken from wet regions/months $(d \beta<0)$ and delivered to dry regions/months $(d \alpha>0)$ (Figure $\mathrm{S} 15 \mathrm{c}$ in Text S1). The latitudinal distribution of the observed trend (Figure $4 \mathrm{a}$ ) and climatology (Figure 4b) are negatively related because $P$ increased in drier zones (e.g., $40^{\circ}-90^{\circ} \mathrm{N}, 20^{\circ}-40^{\circ} \mathrm{S}$ ) at the expense of wetter zones (e.g., $\left.0-20^{\circ} \mathrm{N}\right)$. That relation is clearer when the trend in $P$ (1940-2009) for each month (in a given grid-box) is grouped into $P$ classes (Figure $4 d$ ) and the land area (Figure $4 \mathrm{f}$ ) is used to adjust the trend to a volumetric basis (Figure 4e). The key result (Figure 4e) shows that $P$ was, on average, removed from relatively wetter regions/months $\left(P>100 \mathrm{~mm} \mathrm{month}^{-1}\right)$ with nearly all of that delivered to relatively dry regions/months $\left(P<100 \mathrm{~mm}\right.$ month $\left.^{-1}\right)$. Those results confirm that, on average, dry regions/months became wetter and wet regions/ months became drier over the 1940-2009 period. This conclusion holds in all available databases and also holds for 1940-1999 (Figures S18-S24 in Text S1). 


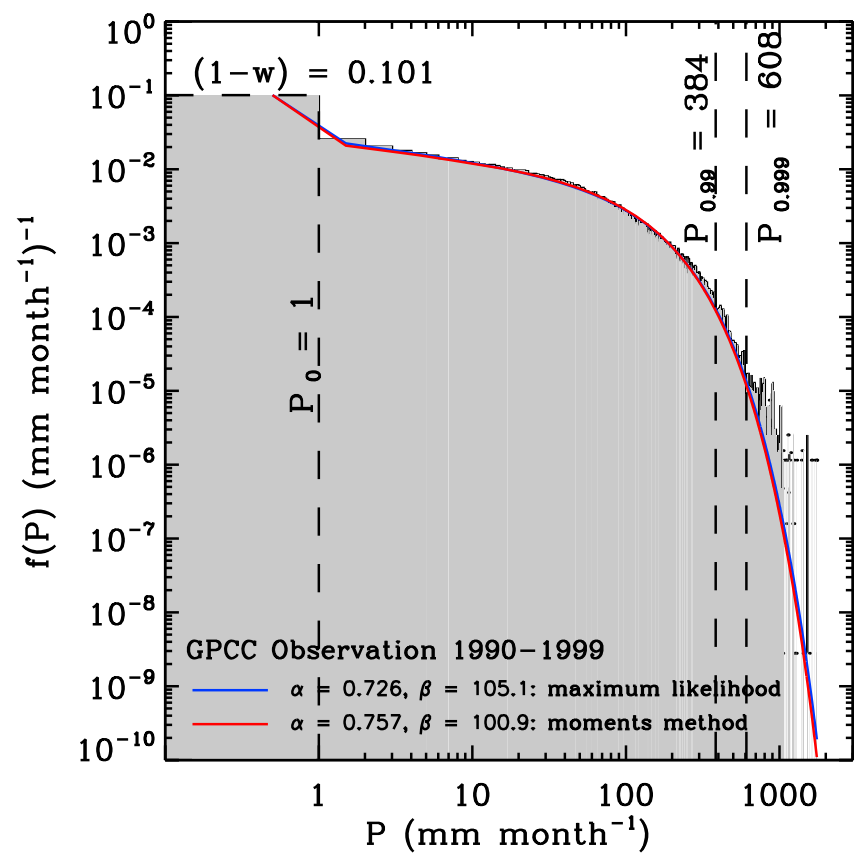

Figure 2. Frequency distribution of decadal $P$. The observations (grey vertical bars at intervals of $1 \mathrm{~mm}$ month $^{-1}$ ) are fitted by the mixture (uniform-gamma) distribution. The relative frequency of wet months $(w)$ is determined from observations using a threshold $\left(P_{0}=1 \mathrm{~mm} \mathrm{month}{ }^{-1}\right)$ and the shape $(\alpha)$ and scaling $(\beta)$ parameter values (see equation (1)) are estimated using two different methods (maximum likelihood and moments). Empirical estimates of extremes $\left(P_{0.99}\right.$, $\left.P_{0.999}\right)$ are indicated.

\section{Discussion}

[10] Early work before the advent of global monthly databases reported increases in monthly $P$ variability over much of North America, Europe and Australia [Tsonis, 1996] and we found the same pattern (Figure 1e). However, global databases are now available and they reveal many other regions that show decreased $P$ variability (Figure 1e). The changes reported here in the (monthly) temporal variance (Figure 1e), that are dominated by the change in the intra-annual variance, reinforce earlier regional studies on changes in daily $P$ extremes including increases over much of North America, Europe [Karl et al., 1995; Min et al., 2011], southeastern Brazil [Teixeira and Satyamurty, 2011] and South Africa [Easterling et al., 2000a, 2000b; New et al., 2006] alongside declines over many parts of Russia, China [Karl et al., 1995; Min et al., 2011] and Thailand [Easterling et al., 2000a, 2000b] with mixed trends in equatorial Africa [Easterling et al., 2000a, 2000b; New et al., 2006] and India [Ghosh et al., 2011; Goswami et al., 2006]. Importantly, these patterns show no relationship to local (Figure S25 in Text S1) or global changes in temperature (Figure 1b). When integrated there has been little change in global mean $P$ over land but with a tendency for dry regions/months to become wetter and wet regions/ months to become drier (Figure 4e). This result is robust in all databases examined (Figures S18-S24 in Text S1). If anything, these results constitute a slight decline in meteorological drought over the last 70 years.
[11] Recent climate modelling suggests that $P$ extremes and/or variance tend to increase with $\left[\mathrm{CO}_{2}\right]\left[O^{\prime}\right.$ Gorman and Schneider, 2009; Wetherald, 2010] but tend to decrease with aerosols [Chen et al., 2011; Ming and Ramaswamy, 2011]. Hence a combination of well-mixed greenhouse gases and spatially inhomogeneous aerosols could change local and hemispheric circulations and lead to novel regional impacts [Bollasina et al., 2011; Rotstayn and Lohmann, 2002]. In that respect there is a striking spatial correspondence between the largest changes in $P$ variability (Figure 1e) and the location of aerosol emissions [Ramanathan and Feng, 2009]. This correspondence coupled with modelling studies [Bollasina et al., 2011; Chen et al., 2011; Ming and
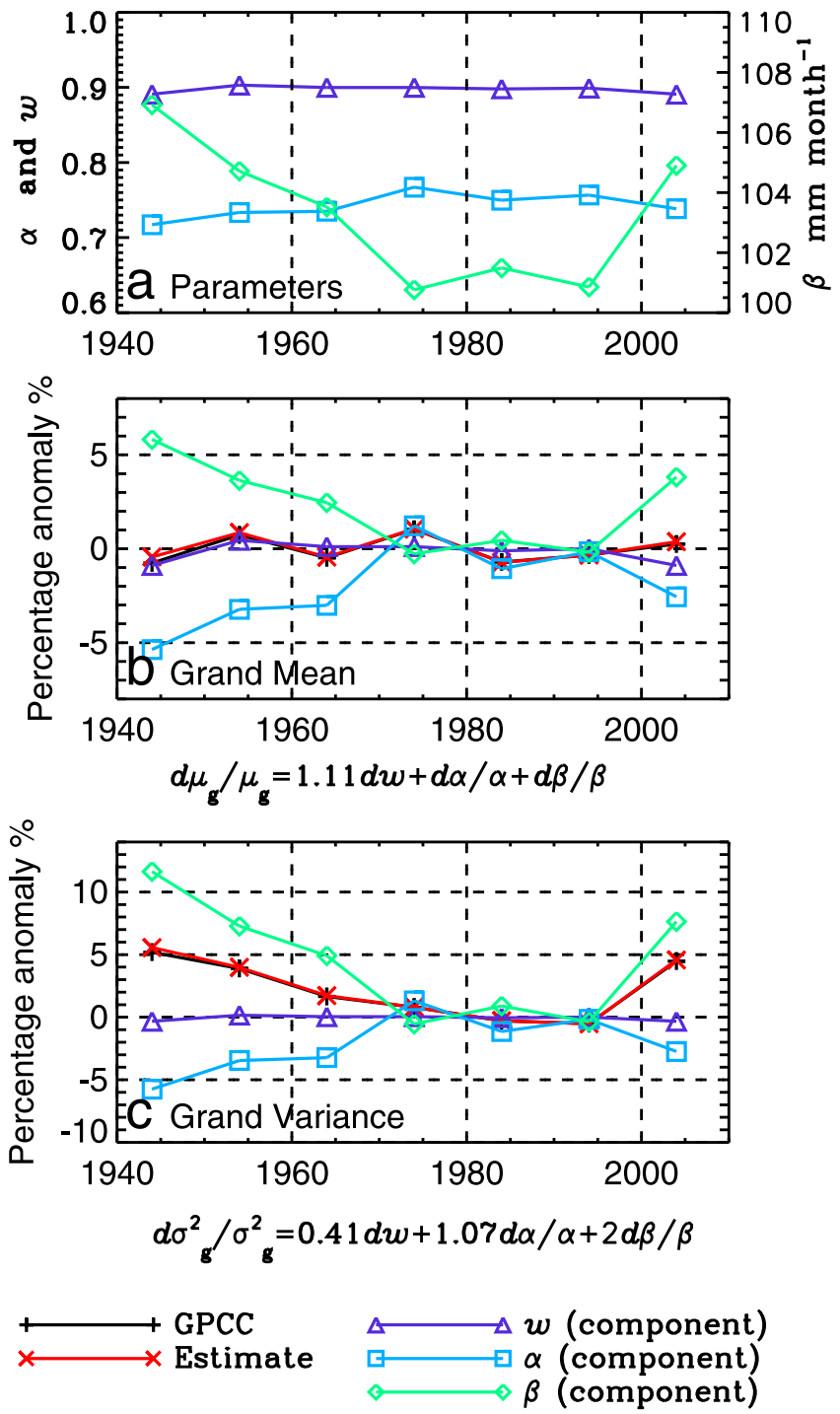

Figure 3. Detection of changes in the global land $P$ distribution. (a) Changes in the distribution parameters (in equation (1)) and detection of changes in (b) the decadal grand mean and (c) grand variance. The percentage anomalies are expressed relative to the average for 1970-1999. The total change (GPCC, black line) is estimated (red line) using differentials (shown below Figure 1c). Separate contributions due to changes in the frequency of wet months $(w)$, and the shape $(\alpha)$ and scale $(\beta)$ parameters of the mixture distribution are depicted. 

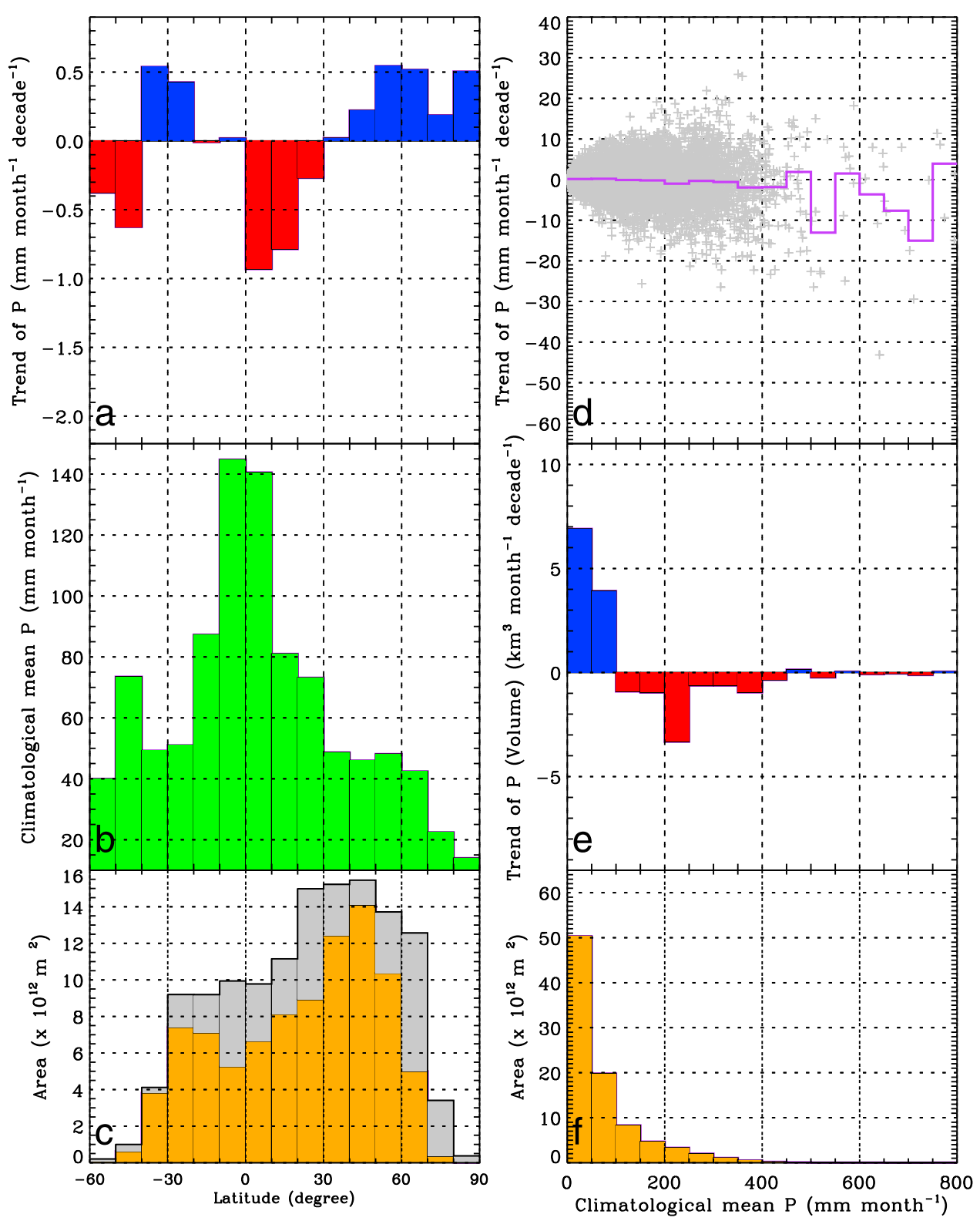

Figure 4. Trends in $P$ in (left) geographic and (right) environmental space for the period: 1940-2009. Regional (latitudinal) distribution of (a) trend in $P$, (b) climatological mean $P$ and (c) the representative land area (grey denotes the total land area while orange denotes the spatial mask). Local (monthly for each grid-box) trend in $P$ in dimensions of (d) depth (+ denotes a grid-box, line denotes the mean for each $50 \mathrm{~mm}$ month $^{-1} P$ class), (e) volume (using liquid water equivalent) weighted by (f) the area of the land mask.

Ramaswamy, 2011; Rotstayn and Lohmann, 2002] leads us to speculate that fully accounting for the observed $P$ variability documented here will require intensive investigations to separate the impacts of aerosols and greenhouse gases from natural variability.

[12] Acknowledgments. This research was supported by the Australian Research Council (DP110105376, CE11E0098). We thank Dr. Andreas Becker from the Global Precipitation Climatology Centre (GPCC) for providing details about the number of stations in the VASClimO database.

[13] The Editor thanks Yi Ming and an anonymous reviewer for assisting in the evaluation of this paper.

\section{References}

Allan, R. P., and B. J. Soden (2008), Atmospheric warming and the amplification of precipitation extremes, Science, 321(5895), 1481-1484, doi:10.1126/science.1160787.

Allen, M. R., and W. J. Ingram (2002), Constraints on future changes in climate and the hydrologic cycle, Nature, 419(6903), 224-232, doi:10.1038/nature01092.

Benestad, R. E. (2006), Can we expect more extreme precipitation on the monthly time scale?, J. Clim., 19(4), 630-637, doi:10.1175/JCLI3656.1.

Boer, G. J. (2009), Changes in interannual variability and decadal potential predictability under global warming, J. Clim., 22(11), 3098-3109, doi:10.1175/2008JCLI2835.1.

Bollasina, M. A., Y. Ming, and V. Ramaswamy (2011), Anthropogenic aerosols and the weakening of the South Asian summer monsoon, Science, 334(6055), 502-505, doi:10.1126/science.1204994.

Chen, G., Y. Ming, N. D. Singer, and J. Lu (2011), Testing the ClausiusClapeyron constraint on the aerosol-induced changes in mean and 
extreme precipitation, Geophys. Res. Lett., 38, L04807, doi:10.1029/ 2010GL046435.

Chou, C., J. Y. Tu, and P. H. Tan (2007), Asymmetry of tropical precipitation change under global warming, Geophys. Res. Lett., 34, L17708, doi:10.1029/2007GL030327.

Dai, A., I. Y. Fung, and A. D. DelGenio (1997), Surface observed global land precipitation variations during 1900-88, J. Clim., 10(11), 2943-2962, doi:10.1175/1520-0442(1997)010<2943:SOGLPV>2.0.CO;2.

Eagleson, P. S. (2002), Ecohydrology: Darwinian Expression of Vegetation Form and Function, Cambridge Univ. Press, Cambridge, U. K., doi:10.1017/CBO9780511535680.

Easterling, D. R., G. A. Meehl, C. Parmesan, S. A. Changnon, T. R. Karl, and L. O. Mearns (2000a), Climate extremes: Observations, modeling, and impacts, Science, 289(5487), 2068-2074, doi:10.1126/science. 289.5487.2068.

Easterling, D. R., J. L. Evans, P. Y. Groisman, T. R. Karl, K. E. Kunkel, and P. Ambenje (2000b), Observed variability and trends in extreme climate events: A brief review, Bull. Am. Meteorol. Soc., 81(3), 417-425, doi:10.1175/1520-0477(2000)081<0417:OVATIE >2.3.CO;2.

Ghosh, S., D. Das, S.-C. Kao, and A. R. Ganguly (2011), Lack of uniform trends but increasing spatial variability in observed Indian rainfall extremes, Nat. Clim. Change, 2, 86-91, doi:10.1038/nclimate1327.

Goswami, B. N., V. Venugopal, D. Sengupta, M. S. Madhusoodanan, and P. K. Xavier (2006), Increasing trend of extreme rain events over India in a warming environment, Science, 314(5804), 1442-1445, doi:10.1126/science. 1132027 .

Groisman, P. Y., et al. (1999), Changes in the probability of heavy precipitation: Important indicators of climatic change, Clim. Change, 42(1), 243-283, doi:10.1023/A:1005432803188.

Hansen, J., R. Ruedy, M. Sato, and K. Lo (2010), Global surface temperature change, Rev. Geophys., 48, RG4004, doi:10.1029/2010RG000345.

Held, I. M., and B. J. Soden (2006), Robust responses of the hydrological cycle to global warming, J. Clim., 19(21), 5686-5699, doi:10.1175/ JCLI3990.1.

Huffman, G. J., R. F. Adler, D. T. Bolvin, and G. Gu (2009), Improving the global precipitation record: GPCP Version 2.1, Geophys. Res. Lett., 36, L17808, doi:10.1029/2009GL040000.

Karl, T. R., R. W. Knight, and N. Plummer (1995), Trends in high-frequency climate variability in the twentieth century, Nature, 377(6546), 217-220, doi:10.1038/377217a0.

Min, S.-K., X. Zhang, F. W. Zwiers, and G. C. Hegerl (2011), Human contribution to more-intense precipitation extremes, Nature, 470(7334), 378-381, doi:10.1038/nature09763.

Ming, Y., and V. Ramaswamy (2011), A model investigation of aerosolinduced changes in tropical circulation, J. Clim., 24, 5125-5133, doi:10.1175/2011JCLI4108.1.

Mitchell, T. D., and P. D. Jones (2005), An improved method of constructing a database of monthly climate observations and associated high-resolution grids, Int. J. Climatol., 25(6), 693-712, doi:10.1002/ joc. 1181 .

New, M., et al. (2006), Evidence of trends in daily climate extremes over southern and west Africa, J. Geophys. Res., 111, D14102, doi:10.1029/ 2005JD006289.

O'Gorman, P. A., and T. Schneider (2009), The physical basis for increases in precipitation extremes in simulations of 21 st-century climate change, Proc. Natl. Acad. Sci. U. S. A., 106(35), 14,773-14,777, doi:10.1073/ pnas.0907610106.

Peterson, T. C., and R. S. Vose (1997), An overview of the Global Historical Climatology Network Temperature Database, Bull. Am.
Meteorol. Soc., 78(12), 2837-2849, doi:10.1175/1520-0477(1997) 078<2837:AOOTGH>2.0.CO;2.

Porporato, A., E. Daly, and I. Rodriguez-Iturbe (2004), Soil water balance and ecosystem response to climate change, Am. Nat., 164(5), 625-632, doi:10.1086/424970.

Ramanathan, V., and Y. Feng (2009), Air pollution, greenhouse gases and climate change: Global and regional perspectives, Atmos. Environ. 43(1), 37-50, doi:10.1016/j.atmosenv.2008.09.063.

Rind, D., R. Goldberg, and R. Ruedy (1989), Change in climate variability in the 21st century, Clim. Change, 14(1), 5-37, doi:10.1007/ BF00140173.

Rodríguez-Iturbe, I., and A. Porporato (2004), Ecohydrology of WaterControlled Ecosystems: Soil Moisture and Plant Dynamics, Cambridge Univ. Press, Cambridge, U. K.

Rotstayn, L. D., and U. Lohmann (2002), Tropical rainfall trends and the indirect aerosol effect, J. Clim., 15(15), 2103-2116, doi:10.1175/15200442(2002)015<2103:TRTATI >2.0.CO;2.

Rudolf, B., and U. Schneider (2005), Calculation of gridded precipitation data for the global land-surface using in-situ gauge observations, in Proceedings of the 2nd International Precipitation Working Group Workshop, edited by J. Turk and P. Bauer, pp. 231-247, Nav. Res. Lab., Monterey, Calif.

Sugiyama, M., H. Shiogama, and S. Emori (2010), Precipitation extreme changes exceeding moisture content increases in MIROC and IPCC climate models, Proc. Natl. Acad. Sci. U. S. A., 107(2), 571-575, doi:10.1073/pnas.0903186107.

Sun, F., M. L. Roderick, G. D. Farquhar, W. H. Lim, Y. Zhang, N. Bennett, and S. H. Roxburgh (2010), Partitioning the variance between space and time, Geophys. Res. Lett., 37, L12704, doi:10.1029/2010GL043323.

Teixeira, M. S., and P. Satyamurty (2011), Trends in the frequency of intense precipitation events in southern and southeastern Brazil during 1960-2004, J. Clim., 24(7), 1913-1921, doi:10.1175/2011JCLI3511.1.

Thom, H. C. S. (1958), A note on the gamma distribution, Mon. Weather Rev., 86(4), 117-122, doi:10.1175/1520-0493(1958)086<0117:ANOTGD> 2.0.CO;2.

Trenberth, K. E. (2011), Changes in precipitation with climate change, Clim. Res., 47(1-2), 123-138, doi:10.3354/cr00953.

Trenberth, K. E., A. Dai, R. M. Rasmussen, and D. B. Parsons (2003), The changing character of precipitation, Bull. Am. Meteorol. Soc., 84(9), 1205-1217, doi:10.1175/BAMS-84-9-1205.

Tsonis, A. A. (1996), Widespread increases in low-frequency variability of precipitation over the past century, Nature, 382(6593), 700-702, doi: $10.1038 / 382700 \mathrm{a} 0$.

von Storch, H., and F. W. Zwiers (1999), Statistical Analysis in Climate Research, Cambridge Univ. Press, Cambridge, U. K.

Wetherald, R. T. (2010), Changes of time mean state and variability of hydrology in response to a doubling and quadrupling of $\mathrm{CO}_{2}$, Clim. Change, 102(3-4), 651-670, doi:10.1007/s10584-009-9701-4.

Wilks, D. S. (2011), Statistical Methods in the Atmospheric Sciences, 3rd ed., Academic, San Diego, Calif.

Xie, P. P., and P. A. Arkin (1997), Global precipitation: A 17-year monthly analysis based on gauge observations, satellite estimates, and numerical model outputs, Bull. Am. Meteorol. Soc., 78(11), 2539-2558, doi:10.1175/1520-0477(1997)078<2539:GPAYMA>2.0.CO;2.

Yin, X., A. Gruber, and P. Arkin (2004), Comparison of the GPCP and CMAP merged gauge-satellite monthly precipitation products for the period 1979-2001, J. Hydrometeorol., 5(6), 1207-1222, doi:10.1175/ JHM-392.1. 


\title{
Supporting Online Materials
}

\section{Changes in the variability of global land precipitation}

\author{
Fubao Sun $^{1,3}$, Michael L. Roderick ${ }^{1,2,3}$, Graham D. Farquhar ${ }^{1,3}$ \\ ${ }^{1}$ Research School of Biology, The Australian National University, Canberra, ACT 0200, \\ Australia.
}

${ }^{2}$ Research School of Earth Sciences, The Australian National University, Canberra, ACT 0200, Australia.

${ }^{3}$ Australian Research Council Centre of Excellence for Climate System Science.

S1. Precipitation Databases and Calculations

S2. The Mixture Distribution

S3. Figures S1 to S25

S4. Tables S1 to S4 


\section{S1. Precipitation Databases and Calculations}

\section{S1.1. Precipitation databases}

We analysed the gridded $\left(2.5^{\circ} \times 2.5^{\circ}\right)$ monthly precipitation observations for the seven readily available databases: GPCC (Global Precipitation Climatology Centre) Version 5 (1901-2009) [Rudolf and Schneider, 2005], CRU (Climatic Research Unit) T3.0 (1901-2006) [Mitchell and Jones, 2005], GPCP (Global Precipitation Climatology Project) V2.1 (1979-2008) [Huffman et al., 2009], CMAP (CPC Merged Analysis of Precipitation, standard monthly) (1979-2008) [Xie and Arkin, 1997], the global land precipitation database (denoted Dai1997) compiled by Dai et al. [1997] (1920-1995 was used for better data availability), GHCN (Global Historical Climatology Network) Version 2 (1940-2009 was used for better data availability) [Peterson and Vose, 1997], and a subset of the GPCC database designed for use in climate change studies called VASClimO (Variability Analysis of Surface Climate Observations) (1951-2000) [Rudolf and Schneider, 2005]. VASClimO used a mostly fixed set of meteorological measurement sites (9133 sites being used) and was developed to minimise problems associated with changes in the interpolation network over time [Rudolf and Schneider, 2005] (Fig.S6a). Note that the CMAP and GPCP databases, both begin in 1979 and both are global (land plus ocean) merged satellite-gauge databases. The remaining five databases are for land only.

\section{S1.2. Trends over land and ocean in the raw databases}

To evaluate the databases, we calculated the grand mean $\left(\mu_{g}\right)$, grand variance $\left(\sigma_{g}{ }^{2}\right)$ and the 99 percentile $\left(P_{0.99}\right)$, for each successive decade (e.g., 1901-1910, 1910-1919, 1920-1929, etc.) for land (Fig.S1a-c) and ocean (Fig.S1d-S1f) as appropriate. Robust trends were difficult to identify (Figs.S1d-S1f, S4, and S5) over the ocean although the climatology from the two databases containing ocean data (CMAP, GPCP) was very similar (Figs.S2-S3). Different trends in global mean oceanic $P$ have been acknowledged previously and relate to different data sources [Yin et al., 2004]. 
Over land the databases are derived using measurements at rainfall gauges with records of 100 years or more in some regions. Given that the prime socio-economic interest is changes in rainfall variability over land we restrict the analysis to the global land surface. The VASClimO database (1950-2000) was specifically designed for climate change studies and was adopted as the reference database for the study. We found general agreement in the overall trend between VASClimO and the other six databases over the 1950-2000 reference period (Figs.S1a-S1c). However, before 1940 there is disagreement between GPCC and CRU in the overall trend of both the grand variance and the precipitation extremes (Fig.S1). Accordingly, we choose to restrict further analysis to the post-1940 period.

\section{S1.3. Global land mask}

We reasoned that the underlying data are sourced from various national meteorological agencies and should be more or less common among the various databases. That suggests that any bias between the VASClimO and other databases in the post-1940 results may be due to different interpolation approaches. Importantly, the GPCC metadata document the number of $P$ measurement sites contained in each gridbox at each month. We used the GPCC metadata to calculate the number of grid-boxes that contained various numbers of measurement sites (Fig.S6). The results show that of the 3232 land based (excl. Antarctica) grid-boxes, around 1000 had at least one rainfall gauge in the year 1900, rising to a maximum of around 2600 grid boxes in the 1980s. (The numbers are less if we count grid-boxes having at least two or more rainfall gauges (Fig.S6).) These results suggest that interpolation in data sparse regions would likely account for much of the bias between the VASClimO and other databases.

To test that interpretation we defined a series of spatial masks based on grid-boxes that included at least one, two, three, four, and five rainfall gauge(s) for at least $90 \%$ of all months between 1951 and 2000. The resulting masks, defined using the GPCC metadata, were used to calculate the grand mean and grand variance for each decade in all six databases. The globally integrated results based on the GPCC, GHCN and CRU databases were more or less identical with those from the VASClimO database for 1950-2000 (Fig.S7). Further, the pattern of change over time in the remaining databases 
was also consistent with that in the VASClimO database over the same 1950-2000 period.

Given the close agreement in the pattern of change over time between all databases (1940-2009), we adopted the spatial mask based on having one measurement site (for 90\% of the time) in each grid-box (Fig.S7k). The results and subsequent conclusion are not sensitive to that because $\sigma_{g}^{2}$ declines for all of the spatial masks (Figs.S7f-S7j). That spatial mask covers 69.3\% of the land surface (excluding Antarctica). The major gaps in the spatial mask are in the places one expects to be poorly sampled; the Arctic (Greenland, Alaska, northern Canada and Russia), parts of the Amazon and Congo as well as major desert regions (Sahara, central Asia).

To test our approach we used the above-noted mask to calculate maps showing trends in the mean and variance (analogous to Figs.1d-e in main text) for the VASClimO, GPCC, GHCN, and CRU databases using the common 1951-2000 period that defined the VASClimO database (Figs.S8-S11). The spatial patterns of the trends are more or less identical.

Note that in Fig.S7f, the decade with the minimum grand variance is 1990-1999 for the GPCC, GPCP, CMAP, Dai1997 and VASClimO databases but in the CRU and GHCN databases, the minimum occurs one decade earlier. Because of the independent agreement, we adopted the GPCC database for the 1940-2009 period as well as the above-noted spatial mask for all subsequent analysis in the main text. We also used the same mask to extract the temperature anomaly from the GISS (Goddard Institute for Space Studies) database [Hansen et al., 2010] and calculated the decadal anomaly for the period 1940-2009 (Fig.1b).

\section{S1.4. Partitioning the Variance between Space and Time}

Precipitation varies considerably through both space and time. Previous studies on the detection of changes in $P$ extremes have used a lumped space-time distribution [Allan and Soden, 2008; Allen and Ingram, 2002; O'Gorman and Schneider, 2009]. We have also used that approach in the main text (Figs.1b-c). This approach gives an 
invaluable summary but it cannot distinguish the variability between space and time. To address that shortcoming we recently derived analytical relationships between the total variance across space and time (here called the grand variance) and the separate spatial and temporal variance components [Sun et al., 2010]. To be comparable with previous studies, we use the time-first formulation of Sun et al. [2010]. The temporal variance can be further partitioned into intra- and inter-annual components using the intra-first scheme of Sun et al. [2010]. Here we describe the key procedures. The grand variance $\sigma_{g}^{2}$ is calculated using a mixed space-time distribution ( $n$ grid boxes and $m$ months) as,

$$
\sigma_{g}^{2}=\frac{n(m-1)}{m \times n-1} \underbrace{\left[\frac{\sum_{j=1}^{n} w_{j} \sigma_{t}^{2}(j)}{n}\right]}_{\equiv \overline{\sigma_{t}^{2}}}+\frac{m(n-1)}{m \times n-1} \sigma_{s}^{2}(\mu)
$$

where the weight $w_{j}$ indicates the area of the $j^{\text {th }}$ grid box scaled as a proportion of the mean area of the grid-boxes. $\sigma_{t}^{2}(j)$ is the temporal variance (calculated over the $m$ months) of the $j^{\text {th }}$ grid box and $\overline{\sigma_{t}^{2}} \equiv \sum_{j=1}^{n} w_{j} \sigma_{t}^{2}(j) / n$ is the mean of the temporal variances $\sigma_{t}^{2}(j)$ of the $n$ grid boxes. $\sigma_{s}^{2}(\mu)$ is the spatial variance of the temporal means. The temporal mean $\mu_{t}(j)$ of the $j^{\text {th }}$ grid box is calculated over the $m$ months. The grand mean $\mu_{g}=\sum_{j=1}^{n} w_{j} \mu_{t}(j) / n$ is an average of $\mu_{t}(j)$ over $n$ grid boxes and is adjusted by the (area-dependent) weights $w_{j}$. The detailed terminology can be found in Sun et al. [2010].

In this specific study, we used decadal blocks ( $m=120$ months) to calculate the grand mean and grand variance. For the 69.3\% coverage (see detailed discussion in Section S1.3) of GPCC global land (excluding Antarctica) database, $n=1,987$ grid boxes. With those data, Eqn.S1A becomes 


$$
\sigma_{g}^{2}=0.99167 \overline{\sigma_{t}^{2}}+0.99950 \sigma_{s}^{2}(\mu)
$$

The above-noted temporal variance can be further partitioned between variation due to the seasonal cycle (called intra-annual variance) and the remaining inter-annual variability. Separation of those components helps to understand changes in the temporal variance. Here, for a given (e.g. the $j^{\text {th }}$ ) grid box, the $m$-month time series can be reorganised into a 2-dimentional array: $p(=12)$ months per year and $q$ years ( $q=m / p=10)$. With that, the temporal variance $\sigma_{t}^{2}(j)$ can be further partitioned into intra- and inter- annual variances as follows,

$$
\sigma_{t}^{2}(j)=\frac{q(p-1)}{p \times q-1} \underbrace{\left[\frac{\sum_{l=1}^{q} \sigma_{a}^{2}(l)}{q}\right]}_{\equiv \sigma_{a}^{2}}+\frac{p(q-1)}{p \times q-1} \sigma_{e}^{2}(\mu)
$$

where $\overline{\sigma_{a}^{2}} \equiv \frac{\sum_{l=1}^{q} \sigma_{a}^{2}(l)}{q}$ is the mean of the intra-annual variances of the seasonal cycle $\sigma_{a}^{2}(l)$ for the $q$ years and $\sigma_{e}^{2}(\mu)$ is the inter-annual variance of the annual mean (Unit: $\left(\mathrm{mm} \text { month }^{-1}\right)^{2}$ ). For further details see Sun et al. [2010, Table 1, Eqn.11]. Eqn.S2A becomes,

$$
\sigma_{t}^{2}(j)=0.92437 \overline{\sigma_{a}^{2}}+0.90756 \sigma_{e}^{2}(\mu)
$$

We calculated each component of the grand variance $\sigma_{g}^{2}$ (in Eqns.S1B and S2B). For reference, the grand variance and components for the climatology (1940-2009) are summarized in Table S1. The trends in all components for the 1940-2009 period are in Table S2 and Fig.S13. Note that in both the climatology and the trends, the temporal variance is dominated by the intra-annual component. For comparison with other previous studies, we also computed the trends in the grand variance (and components) for two other periods (1940-1999 and 1980-2009) (see Tables S3 and S4). 


\section{S2. The Mixture Distribution}

\section{S2.1. Validity of the Mixture Distribution Approximation}

In the main text, we defined a mixture distribution composed of a gamma distribution (Eqn.1) to describe the frequency of $P$ in wet months ( $w$ ) and a uniform distribution for the dry months (1-w). Once the parameters are defined, the frequency can be integrated. In a formal mathematical sense this requires an (implicit) approximation that is always present when empirical data are used to determine the parameters $(\alpha, \beta)$. The total frequency implied by the parameters will usually not exactly equal the frequency determined empirically using the $P_{0}$ threshold. This discrepancy makes no practical difference to the numerical results but is described here for completeness.

The $P$ frequency for wet months is known to follow the gamma distribution ( $f_{w}(P)$, Eqn.1) [Eagleson, 2002; Groisman et al., 1999; Karl et al., 1995; RodríguezIturbe and Porporato, 2004; Thom, 1958; Tsonis, 1996; Porporato et al. 2004] (see Fig.2 in the main text and also Figs.S16-S17). For given values of $\alpha$ and $\beta$ in the gamma distribution and a defined threshold $P_{0}$, we can calculate the integral of the frequency for the interval $P>P_{0}$ as

$$
c_{w}=\int_{P_{0}}^{+\infty} f_{w}(P) d P
$$

where $c_{\mathrm{w}}<1$ because $P_{0}>0$. Note that $c_{w}$ is not analytically tractable [Wilks, 2011]. By definition, $\int_{0}^{+\infty} f_{w}(P) d P=1$ so that $\int_{0}^{P_{0}} f_{w}(P) d P=1-c_{w}$. To give an example, the empirical estimate for $w$ in Fig.2 (in the main text) is 0.899. In contrast, if the gamma distribution is the only distribution being used, for parameter values ( $\alpha=0.7567, \beta=100.9$ ), the numerical value of $c_{\mathrm{w}}$ is 0.965 . (Note that the inter-decadal anomaly in $c_{\mathrm{w}}$ is small and within $\pm 0.35 \%$.) This is the source of the above-noted approximation. The method used to handle this is described below. 
To allow the gamma distribution to reproduce the integral $(w)$ of the empirical frequency distribution for $P>P_{0}$, the integral (Eqn.S3) needs to be scaled by the factor, $\frac{w}{c_{w}}$. With that, the integral becomes (i) $\int_{P_{0}}^{+\infty} \frac{w}{c_{w}} f_{w}(P) d P=\frac{w}{c_{w}} c_{w}=w$, and using the same scaling for the integral from 0 to $P_{0}$ we have (ii) $\int_{0}^{P_{0}} \frac{w}{c_{w}} f_{w}(P) d P=\frac{w}{c_{w}}\left(1-c_{w}\right)$. In practice, that latter component can be approximated as a uniform distribution because $P_{0}$ is small (e.g., 1 or $2 \mathrm{~mm} \mathrm{month}^{-1}$ ) and because the frequency distribution is calculated using a small but finite interval (e.g., we used $1 \mathrm{~mm} \mathrm{month}^{-1}$ ). The sum of the two above-noted integrals is $w+\frac{w}{c_{w}}\left(1-c_{w}\right)=\frac{w}{c_{w}}$. Hence there is a residual, whose integrated frequency in the interval $0 \leq P \leq P_{0}$ must equal (iii) $1-\frac{w}{c_{w}}$. We also use a uniform distribution for that component.

Combining the (ii) and (iii) components in the interval $0 \leq P \leq P_{0}$, the integrated frequency becomes $\left(1-\frac{w}{c_{w}}\right)+\frac{w}{c_{w}}\left(1-c_{w}\right)=1-w$. That defines the mixture distribution used in the main text, i.e., $f(P)=(1-w) f_{d}(P)+w f_{w}(P)$.

\section{S2.2. Derivation of the Detection Method}

For the mixture (uniform-gamma) distribution, we derived the analytical formulae (Eqn.2 in the main text) for the grand mean $\left(\mu_{g}\right)$ and grand variance $\left(\sigma_{g}{ }^{2}\right)$. To examine the changes over time, the differentials are,

$$
d \mu_{g}=\frac{\partial \mu_{g}}{\partial w} d w+\frac{\partial \mu_{g}}{\partial \alpha} d \alpha+\frac{\partial \mu_{g}}{\partial \beta} d \beta
$$

where $\frac{\partial \mu_{g}}{\partial w}=\alpha \beta, \frac{\partial \mu_{g}}{\partial \alpha}=w \beta$, and $\frac{\partial \mu_{g}}{\partial \beta}=w \alpha$. 


$$
d \sigma_{g}^{2}=\frac{\partial \sigma_{g}^{2}}{\partial w} d w+\frac{\partial \sigma_{g}^{2}}{\partial \alpha} d \alpha+\frac{\partial \sigma_{g}^{2}}{\partial \beta} d \beta
$$

where $\frac{\partial \sigma_{g}^{2}}{\partial w}=\alpha \beta^{2}(1+\alpha-2 w \alpha), \frac{\partial \sigma_{g}^{2}}{\partial \alpha}=w \beta^{2}(1+2 \alpha-2 w \alpha)$, and

$$
\frac{\partial \sigma_{g}^{2}}{\partial \beta}=2 w \alpha \beta(1+\alpha-w \alpha)
$$

For detection purposes, we express those differentials in a relative form, except for the fraction of wet months, $w$, which is already a dimensionless variable, as,

$$
\frac{d \mu_{g}}{\mu_{g}}=\frac{\partial \mu_{g}}{\partial w} \frac{1}{\mu_{g}} d w+\frac{\partial \mu_{g}}{\partial \alpha} \frac{\alpha}{\mu_{g}} \frac{d \alpha}{\alpha}+\frac{\partial \mu_{g}}{\partial \beta} \frac{\beta}{\mu_{g}} \frac{d \beta}{\beta}
$$

where $\frac{\partial \mu_{g}}{\partial w} \frac{1}{\mu_{g}}=\frac{1}{w}, \frac{\partial \mu_{g}}{\partial \alpha} \frac{\alpha}{\mu_{g}}=1$, and $\frac{\partial \mu_{g}}{\partial \beta} \frac{\beta}{\mu_{g}}=1$.

$$
\frac{d \sigma_{g}^{2}}{\sigma_{g}^{2}}=\frac{\partial \sigma_{g}^{2}}{\partial w} \frac{1}{\sigma_{g}^{2}} d w+\frac{\partial \sigma_{g}^{2}}{\partial \alpha} \frac{\alpha}{\sigma_{g}^{2}} \frac{d \alpha}{\alpha}+\frac{\partial \sigma_{g}^{2}}{\partial \beta} \frac{\beta}{\sigma_{g}^{2}} \frac{d \beta}{\beta}
$$

where $\frac{\partial \sigma_{g}^{2}}{\partial w} \frac{1}{\sigma_{g}^{2}}=\frac{(1+\alpha-2 w \alpha)}{w(1+\alpha-w \alpha)}, \frac{\partial \sigma_{g}^{2}}{\partial \alpha} \frac{\alpha}{\sigma_{g}^{2}}=\frac{(1+2 \alpha-2 w \alpha)}{(1+\alpha-w \alpha)}$, and $\frac{\partial \sigma_{g}^{2}}{\partial \beta} \frac{\beta}{\sigma_{g}^{2}}=2$.

The relative change in $\sigma_{\mathrm{g}}$ can be calculated as $\frac{d \sigma_{g}}{\sigma_{g}}=\frac{\sigma_{g} d \sigma_{g}}{\sigma_{g}^{2}}=\frac{1}{2} \frac{d \sigma_{g}^{2}}{\sigma_{g}^{2}}$.

After substituting the numerical values ( $\alpha=0.758, w=0.899)$ derived from the GPCC observations (1970-1999) into Eqns.S6-S7, we have,

$$
\frac{d \mu_{g}}{\mu_{g}} \approx 1.11 d w+\frac{d \alpha}{\alpha}+\frac{d \beta}{\beta}
$$




$$
\frac{d \sigma_{g}^{2}}{\sigma_{g}^{2}} \approx 0.41 d w+1.07 \frac{d \alpha}{\alpha}+2 \frac{d \beta}{\beta}
$$

Fig.3 (Main Text) for the GPCC observations has been computed using Eqns.S8-S9 and the detection analysis is discussed in the main text.

\section{S2.3. Parameter Estimation}

The mixture distribution introduced here includes three parameters, $w, \alpha$, and $\beta$. $w$ is the fractional number of months having precipitation more than a threshold $P_{0}$. In a recent study by [Allan and Soden, 2008], a threshold of $0.08 \mathrm{~mm}^{-1} \mathrm{day}^{-1}$ was used. That is equivalent to $2.4 \mathrm{~mm} \mathrm{month}^{-1}$ if it is assumed to rain every day and $1.2 \mathrm{~mm} \mathrm{month}^{-1}$ if it is assumed to rain every second day. Following that, we derived distributions by systematically varying the threshold $P_{0}$ between 1 to $2 \mathrm{~mm}$ month $^{-1}$. In all cases, the results were more or less identical and we finally set the threshold $P_{0}$ to be $1 \mathrm{~mm}^{\text {month }}{ }^{-}$ 1 .

To estimate the other two parameters of the distribution $(\alpha, \beta)$ we used both the Moment Method and Maximum Likelihood Estimation [von Storch and Zwiers, 1999; Wilks, 2011]. The decadal results (1990-1999) for the GPCC observations are summarized in Fig.2 (and also in Fig.S16 with linear scales) and the results for other observational databases are shown in Fig.S17. Both methods gave very similar results and we found that the resulting detection was more or less the same. Consequently, in numerical calculations we used parameter estimates $(\alpha, \beta)$ based on the Moment Method. To evaluate the goodness-of-fit, we prepared the Q-Q plots (empirical quantiles versus modeled quantiles) [Wilks, 2011] by calculating every 0.1-percentile $P$ from the lower end to the 99.9 percentile for all seven databases. The results show perfect fit between the mixture distribution and empirical distribution (linear regression: $\mathrm{y}=1.007 \mathrm{x}+2.0$; $R^{2}=0.999$; mean absolute error: $3.0 \mathrm{~mm}$ month $^{-1}$, Figs.S16-S17).

\section{S3. Supporting Figures}



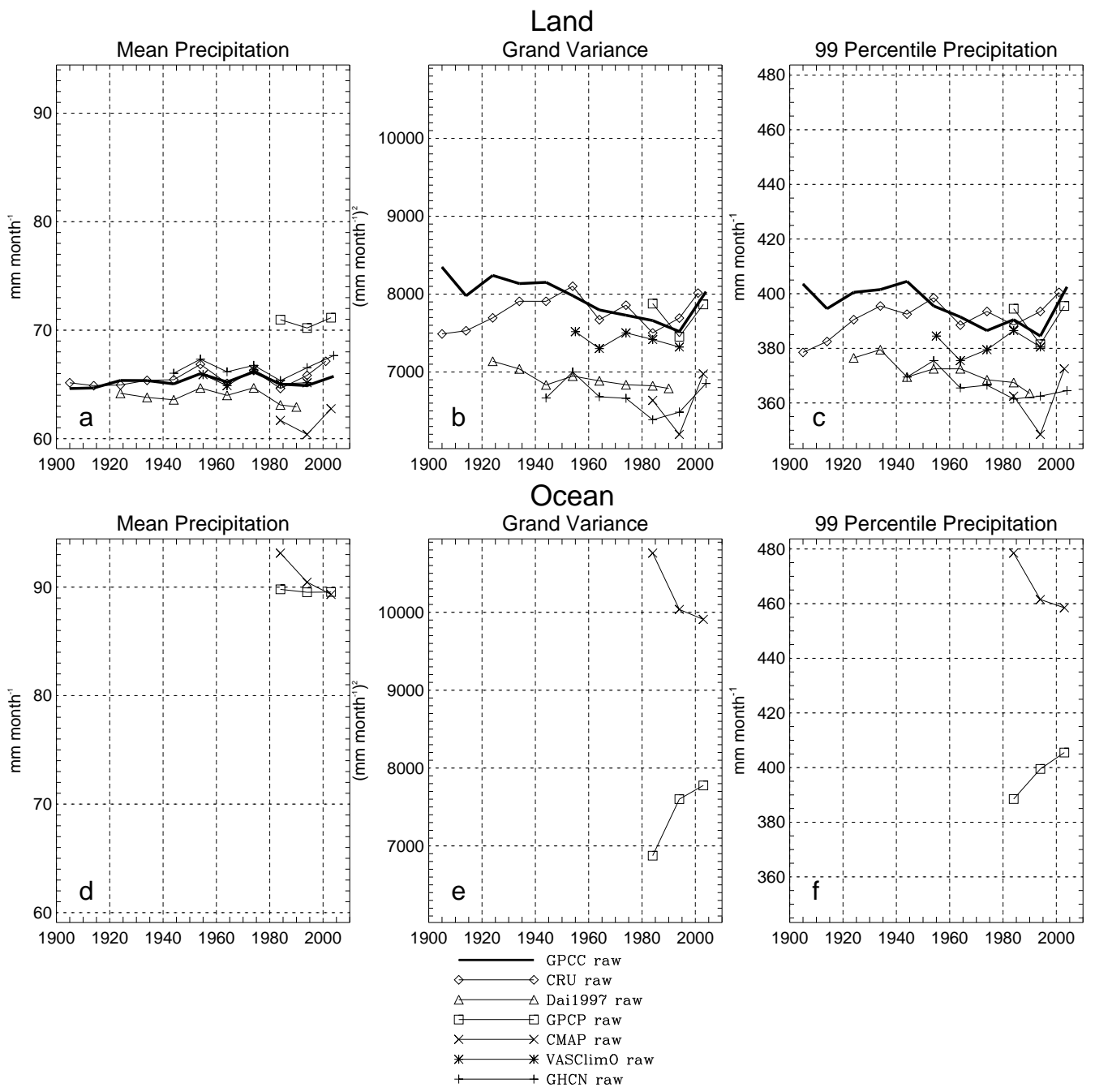

Figure S1 | Time series of the (a) $\mu_{\mathrm{g}}$, (b) $\sigma_{\mathrm{g}}{ }^{2}$, and (c) $P_{0.99}$ based on raw data from seven global land (full land coverage excluding Antarctica) databases of monthly precipitation observations. Panels (d), (e) and (f) are for the ocean $\left(60^{\circ} \mathrm{S}\right.$ to $\left.90^{\circ} \mathrm{N}\right)$ based on raw data from the GPCP and CMAP databases. 
Climatology of the mean: $\mu_{+}(\mathrm{j})$

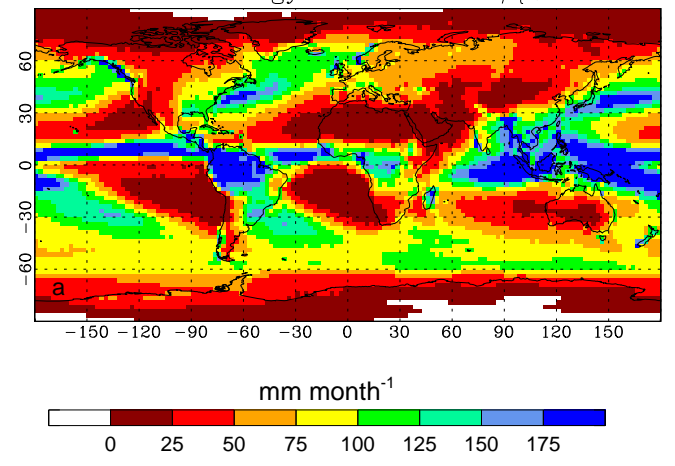

Climatology of the temporal variance: $\sigma_{t}^{2}(\mathrm{j})$
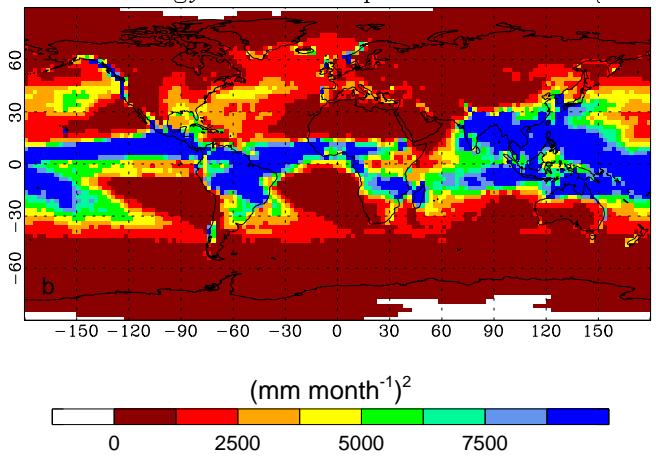

Figure S2 | Climatology of the (a) mean and (b) variance based on raw data from the GPCP database (1980-2008). (White areas denote missing data.)
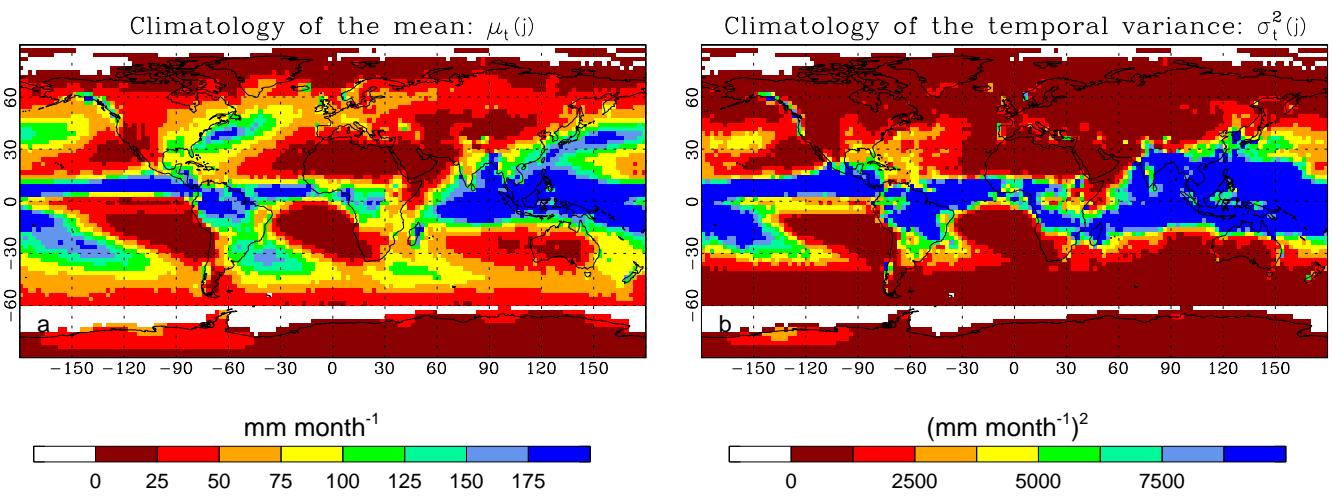

Figure S3 | Analogous to Fig.S2 but for the CMAP database. (White areas denote missing data.) 
Trend of the mean: $\mathrm{d} \mu_{\mathrm{t}}(\mathrm{j}) / \mathrm{dt}$

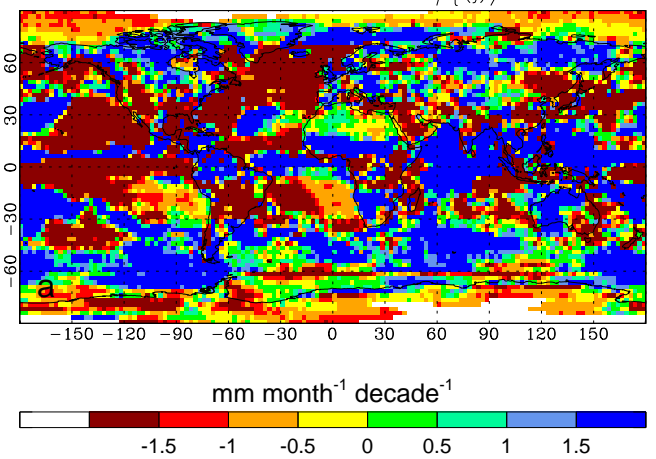

Trend of the temporal variance: $d \sigma_{t}^{2}(j) / d t$

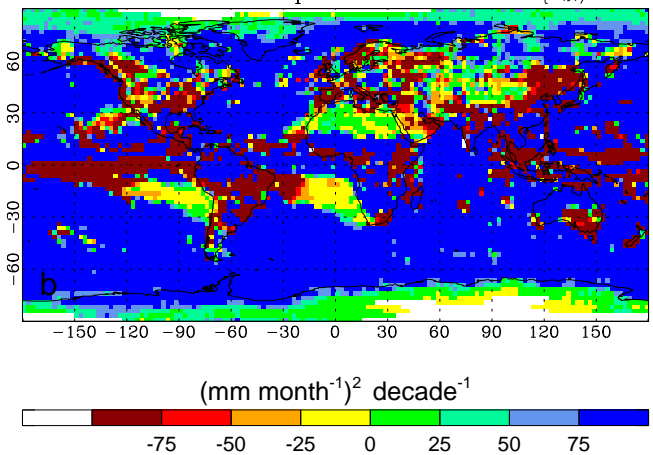

Figure S4 | Trend of the (a) mean and (b) variance based on raw data from the GPCP database (1980-2008). (White areas denote missing data.)

Trend of the mean: $\mathrm{d} \mu_{\mathrm{t}}(\mathrm{j}) / \mathrm{d} \mathrm{t}$
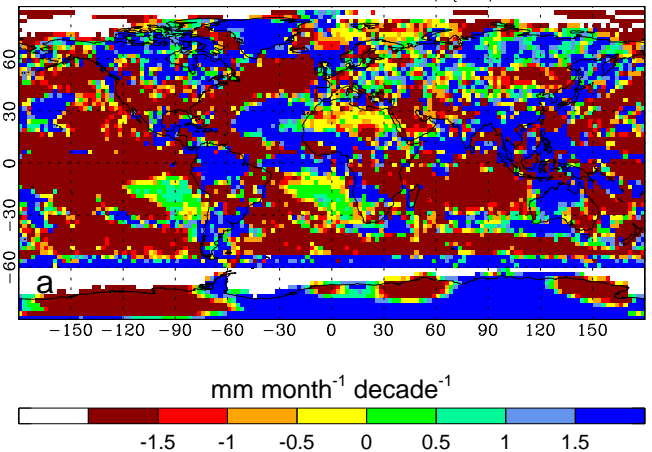

Trend of the temporal variance: $d \sigma_{t}^{2}(j) / d t$

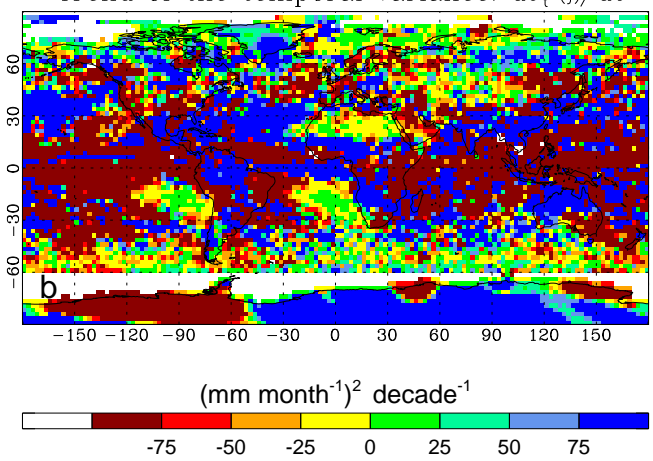

Figure S5 | Analogous to Fig.S4 but for the CMAP database. (White areas denote missing data.) 

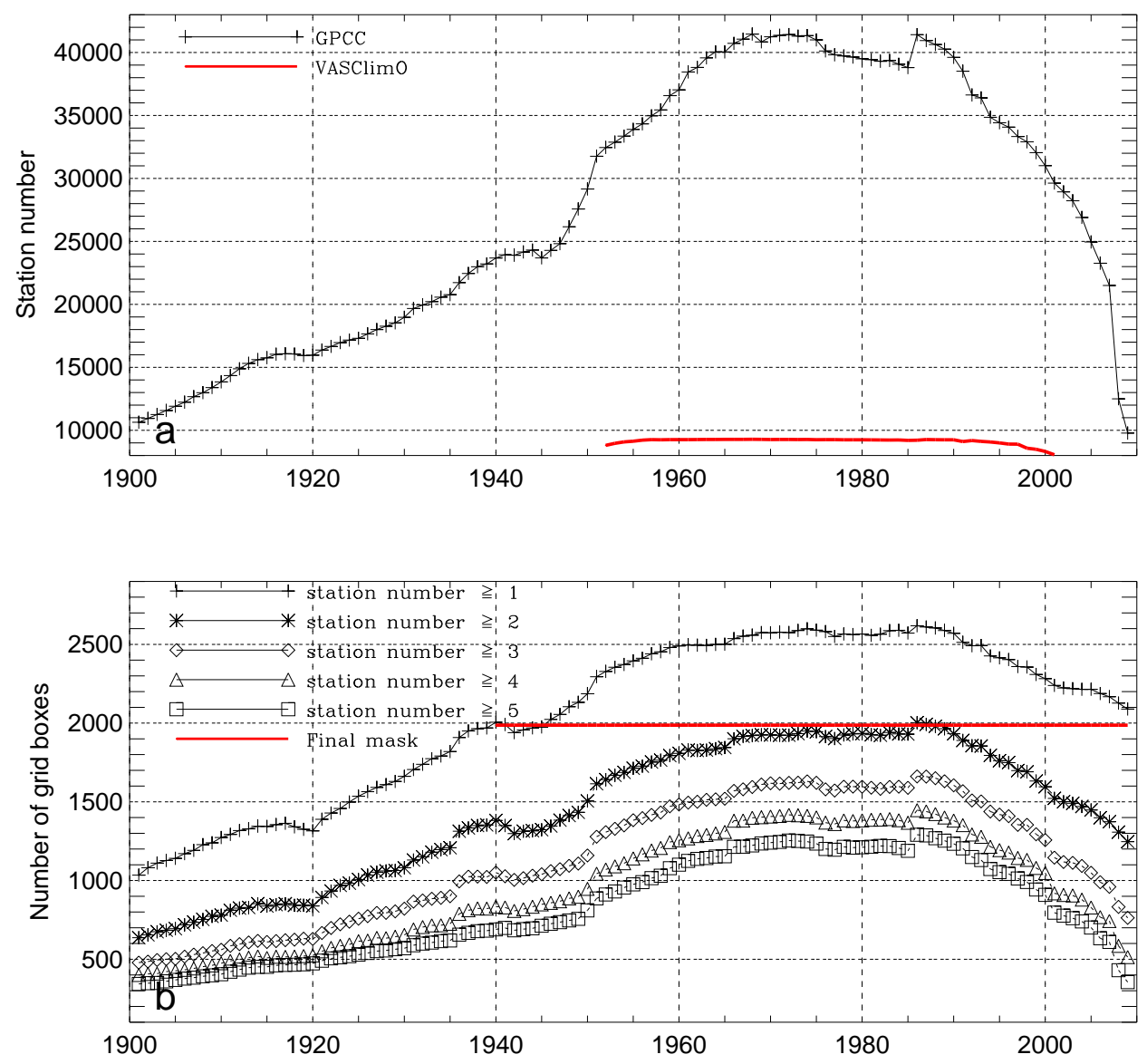

Figure S6 | Time series of (a) the number of stations for the GPCC and VASClimO databases, (b) the number of grid boxes having at least one, two, three, four or five rainfall gauges per the GPCC metadata and the final mask (1,987 grid-boxes). 


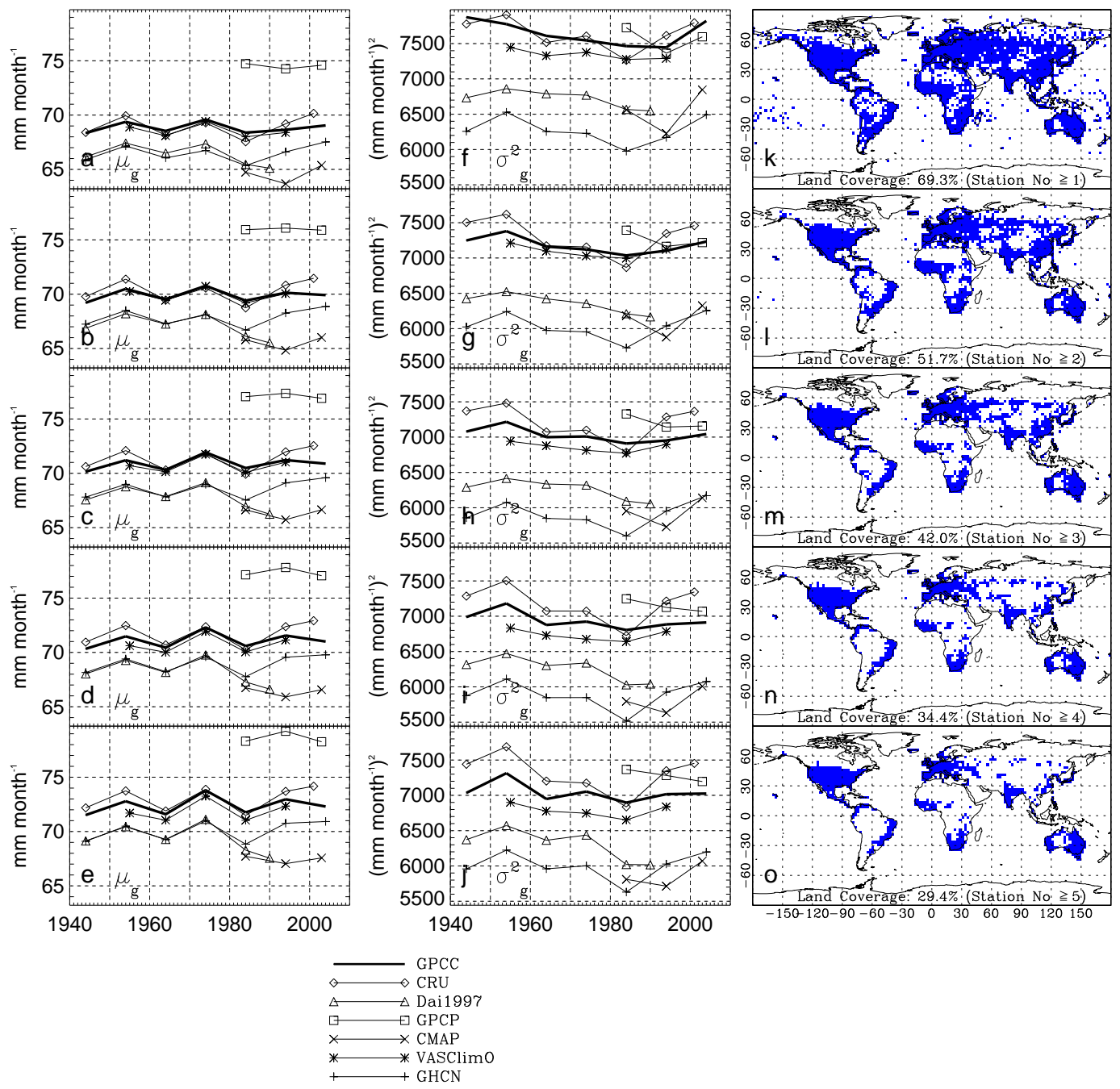

Figure S7 | Time series of the (left panels) grand mean $\mu_{\mathrm{g}}$ and (middle panels) grand variance $\sigma_{\mathrm{g}}{ }^{2}$ in all seven databases based on (right panels) five different spatial masks. The spatial masks are defined by those grid-boxes having at least (k) one, (l) two, (m) three, (n) four or (o) five rainfall gauge(s) for 90\% of all months between 1951-2000. 

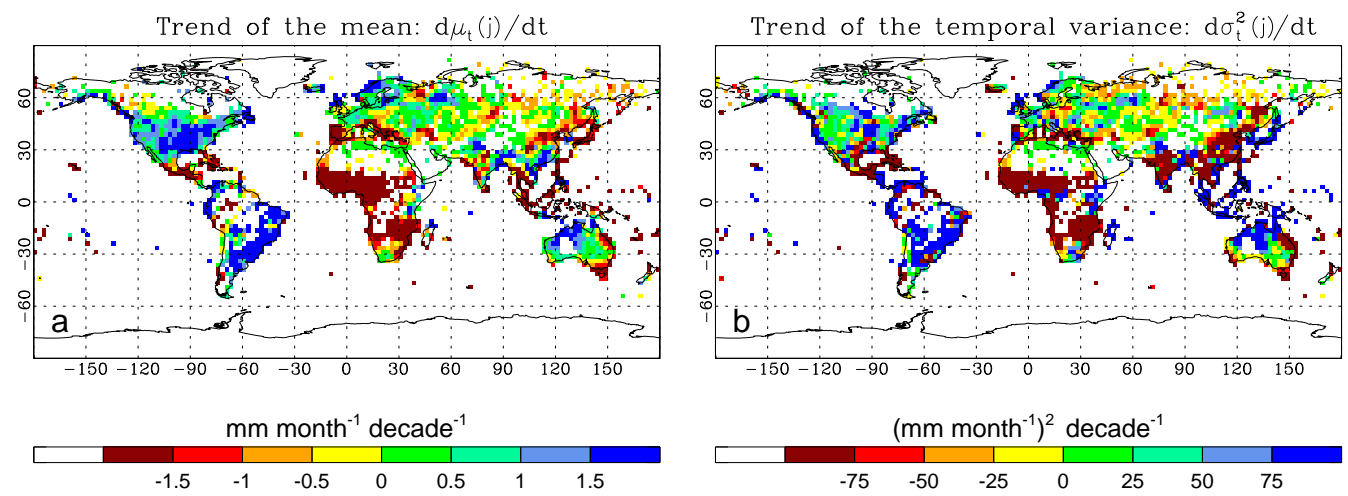

Figure S8 | Analogous to Fig.1d-e (in the main text) but for the period 1951-2000.

(Data: VASClimO, the same spatial mask as Fig.1d-e)
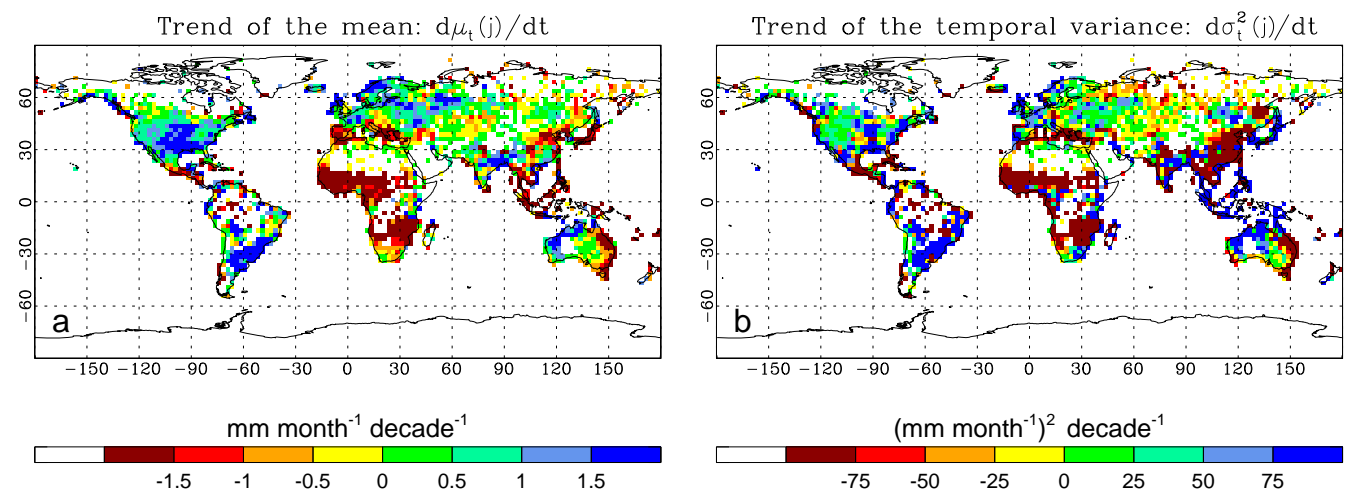

Figure S9 | Analogous to Fig.1d-e (in the main text) but for the period 1951-2000.

(Data: GPCC, the same spatial mask as Fig.1d-e). 

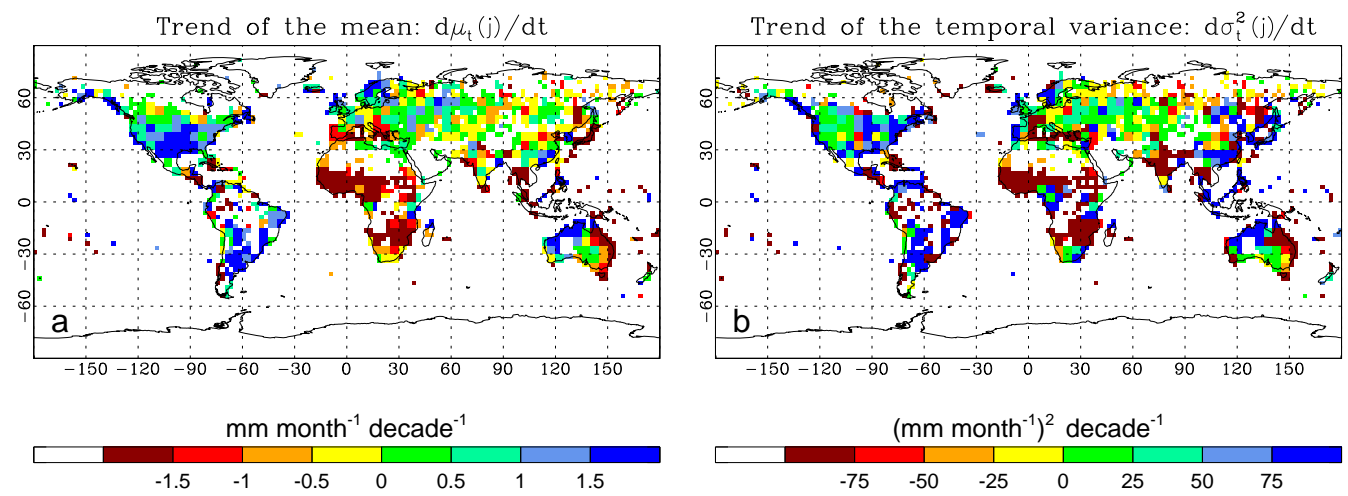

Figure S10 | Analogous to Fig.1d-e (in the main text) but for the period 1951-2000.

(Data: GHCN, the same spatial mask as Fig.1d-e).
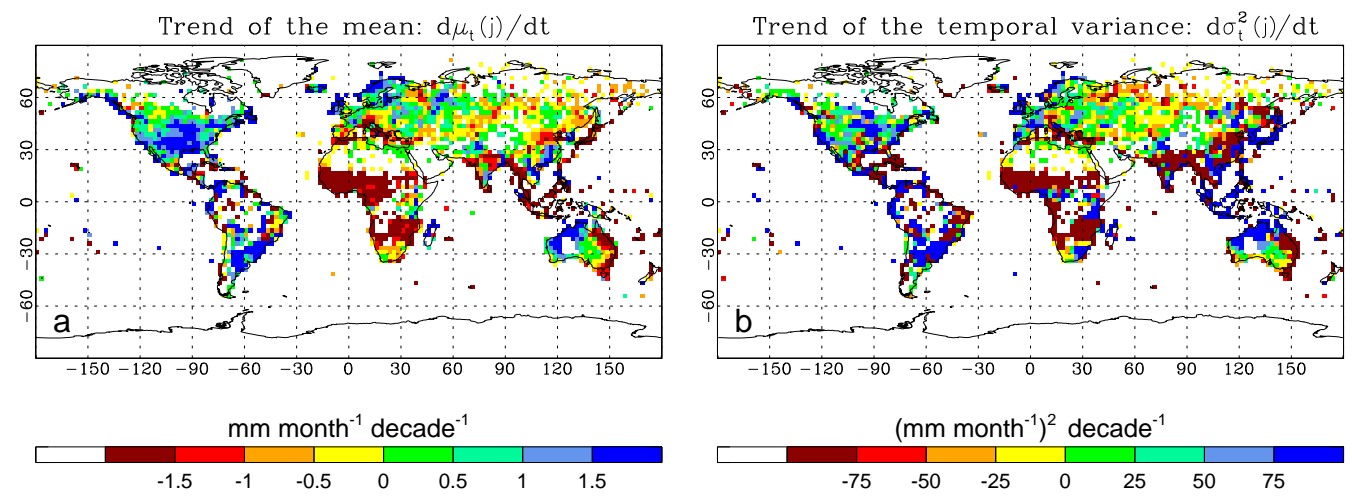

Figure S11 | Analogous to Fig.1d-e (in the main text) but for the period 1951-2000.

(Data: CRU, the same spatial mask as Fig.1d-e). 

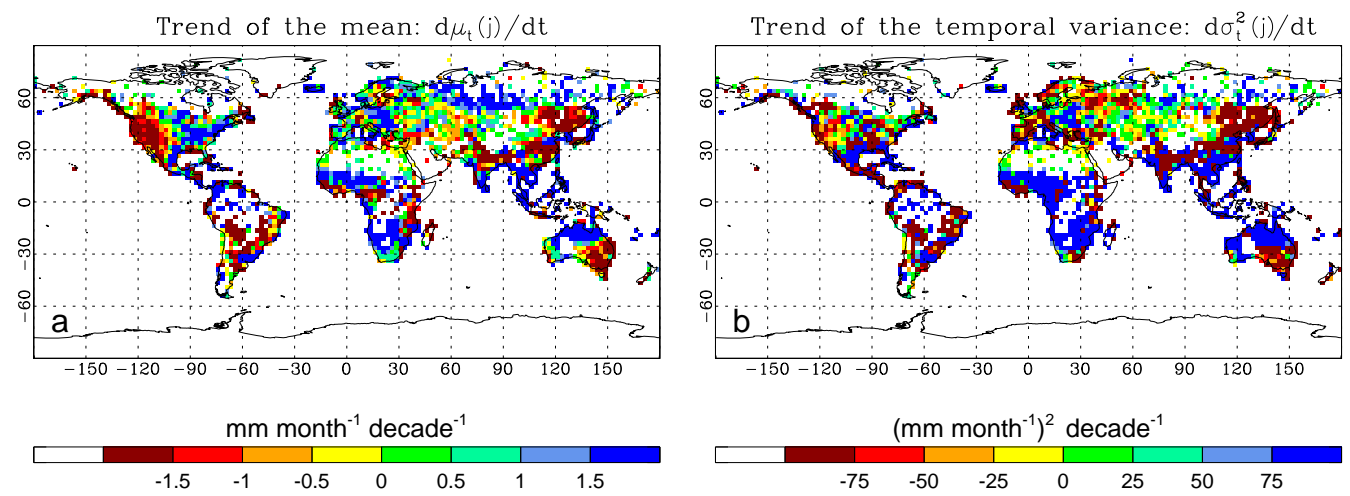

Figure S12 | Analogous to Fig.1d-e (in the main text) but for the period 1980-2009. (Data: GPCC, the same spatial mask as Fig.1d-e).
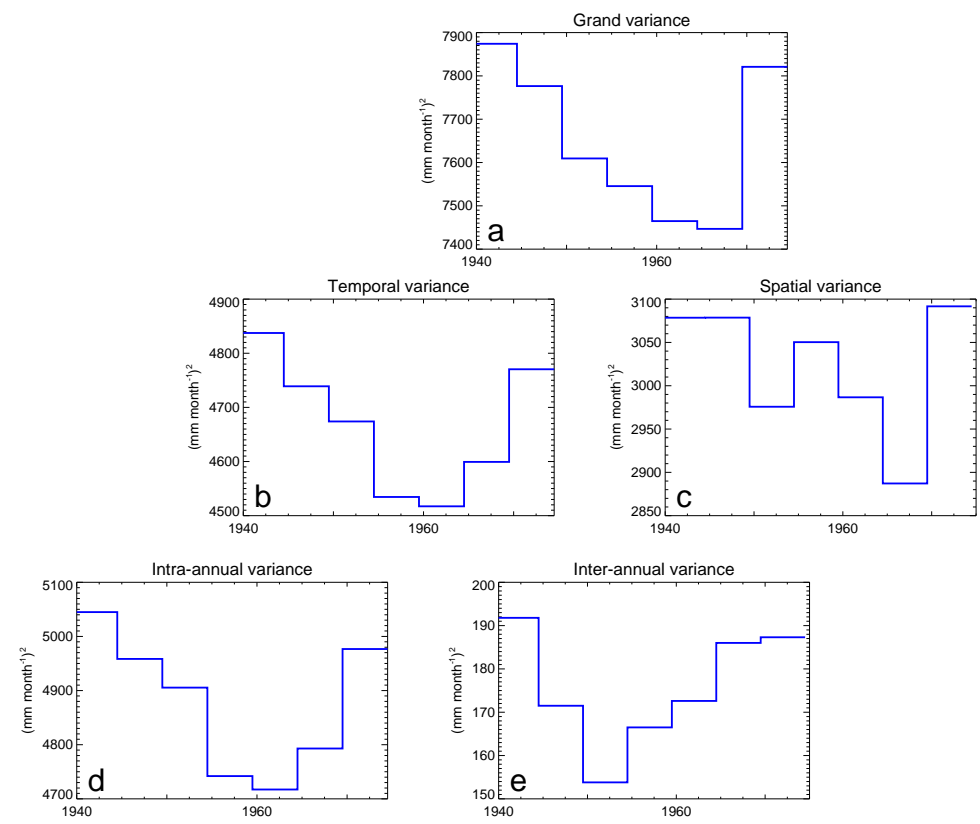

Figure S13 | Time series of decadal (a) grand variance (same as Fig.1b in the main text), and the underlying (b) temporal and (c) spatial components. The temporal variance is further partitioned into the (d) intra-annual and (e) inter-annual components. (Also see Table S2 for full accounting.) 


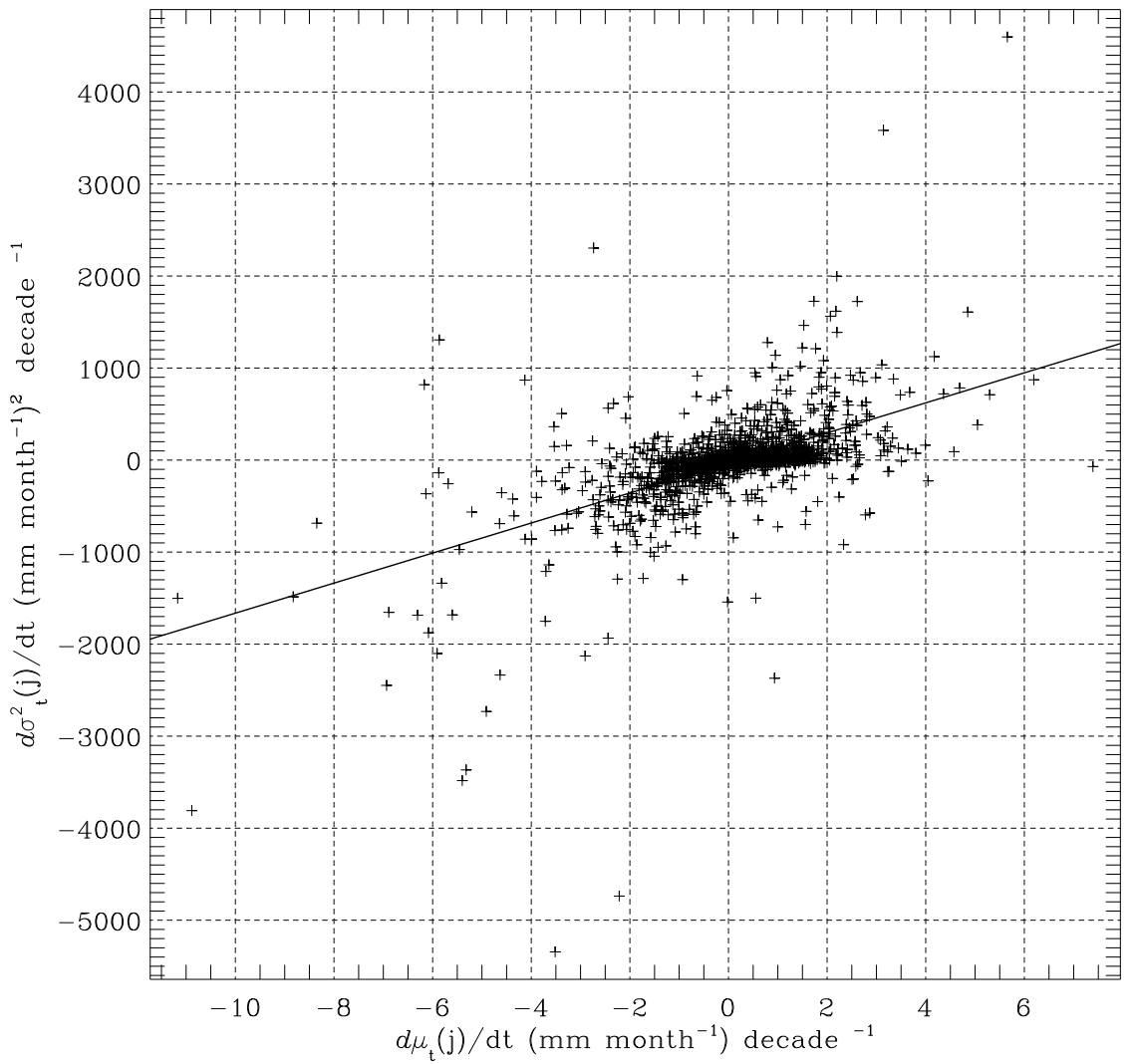

Figure S14 | Relationship between trends in the temporal variance $\left(\sigma_{t}^{2}(j)\right)$ and the mean $\left(\mu_{t}(j)\right)$ for all available grid boxes of the GPCC observations (1940-2009) (equivalent to Fig.1d versus Fig.1e in the main text). Linear regression (solid): $\left.y=163.2 x-30.7, n=1987, R^{2}=0.31\right)$. 

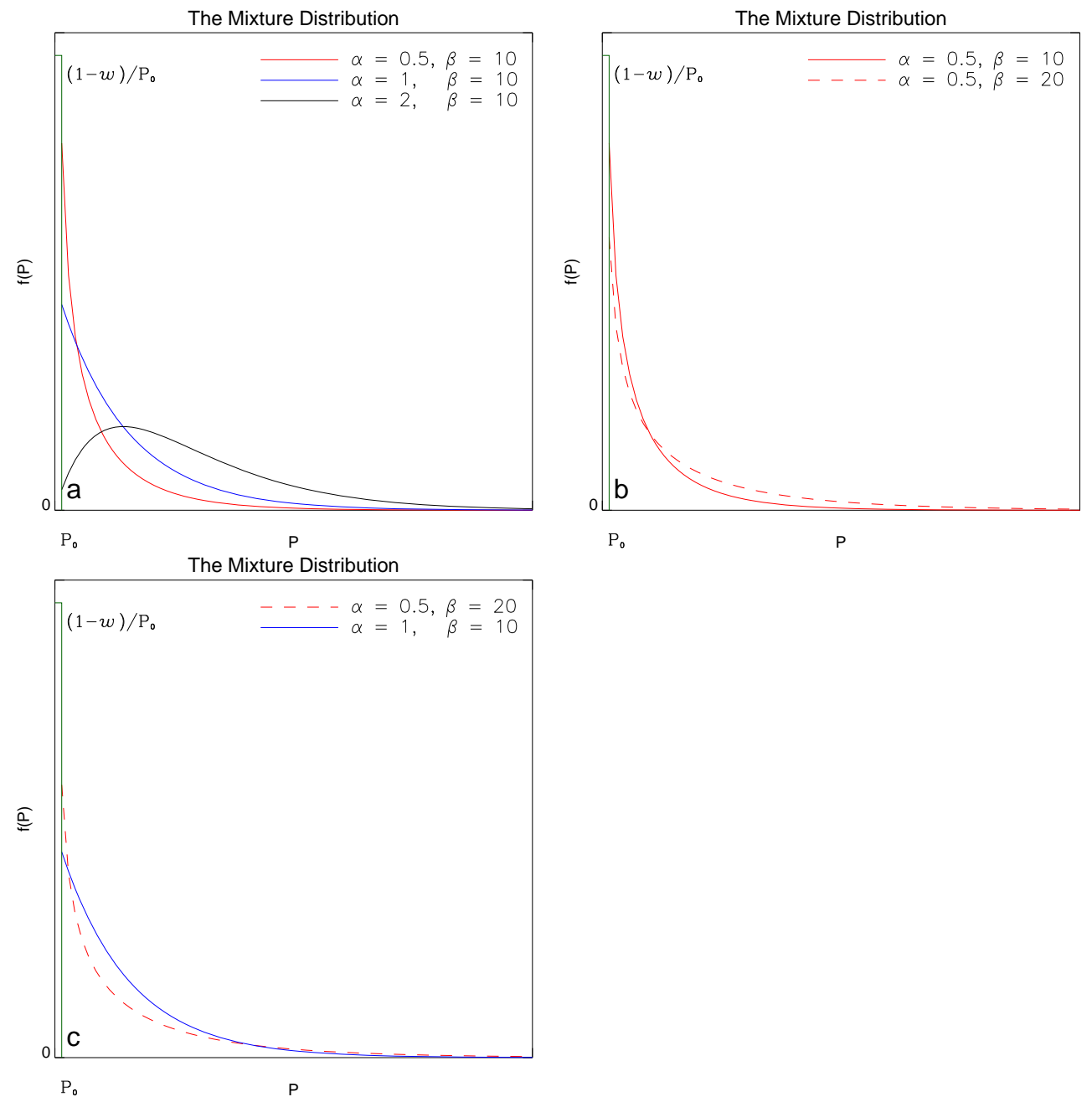

Figure S15 | Theoretical curves of the mixture (uniform-gamma) distribution (Eqn.1 in the main text) for different values of the shape $(\alpha)$ and scaling $(\beta)$ parameters. Effect of varying (a) $\alpha$ and (b) $\beta$ and (c) varying both $\alpha$ and $\beta$ (in opposite directions) while holding the product, $\alpha \beta$, constant. That mimics the observed changes (see Fig. 3 in main text). 

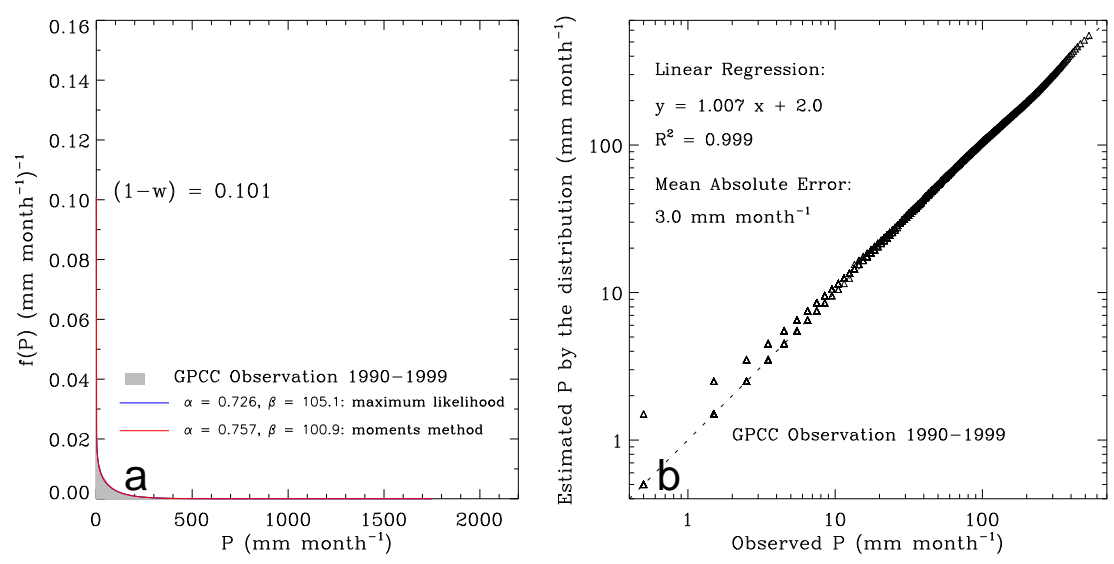

Figure S16 | Goodness-of-fit of the mixture distribution to the GPCC observations:

(a) Analogous to Fig.2 (in the main text) but with linear scales; and (b) Empirical quantiles versus modeled quantiles (for every 0.1 percentile from the lower end to the 99.9 percentile). 

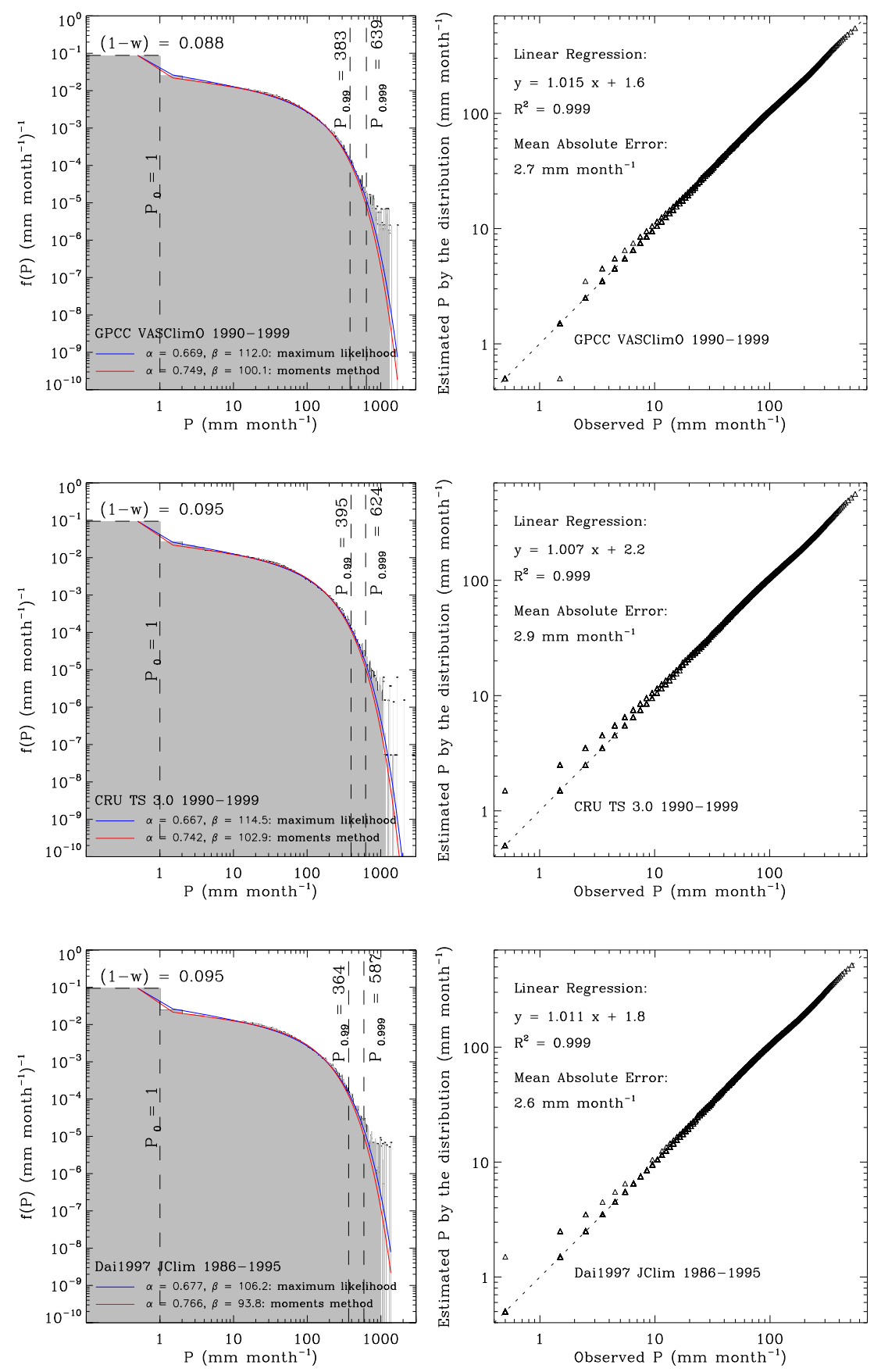

Figure S17 | Goodness-of-fit of the mixture distribution to the other six observations: left panels analogous to Fig.2 (in the main text) and right panels analogous to Fig.S16b. 

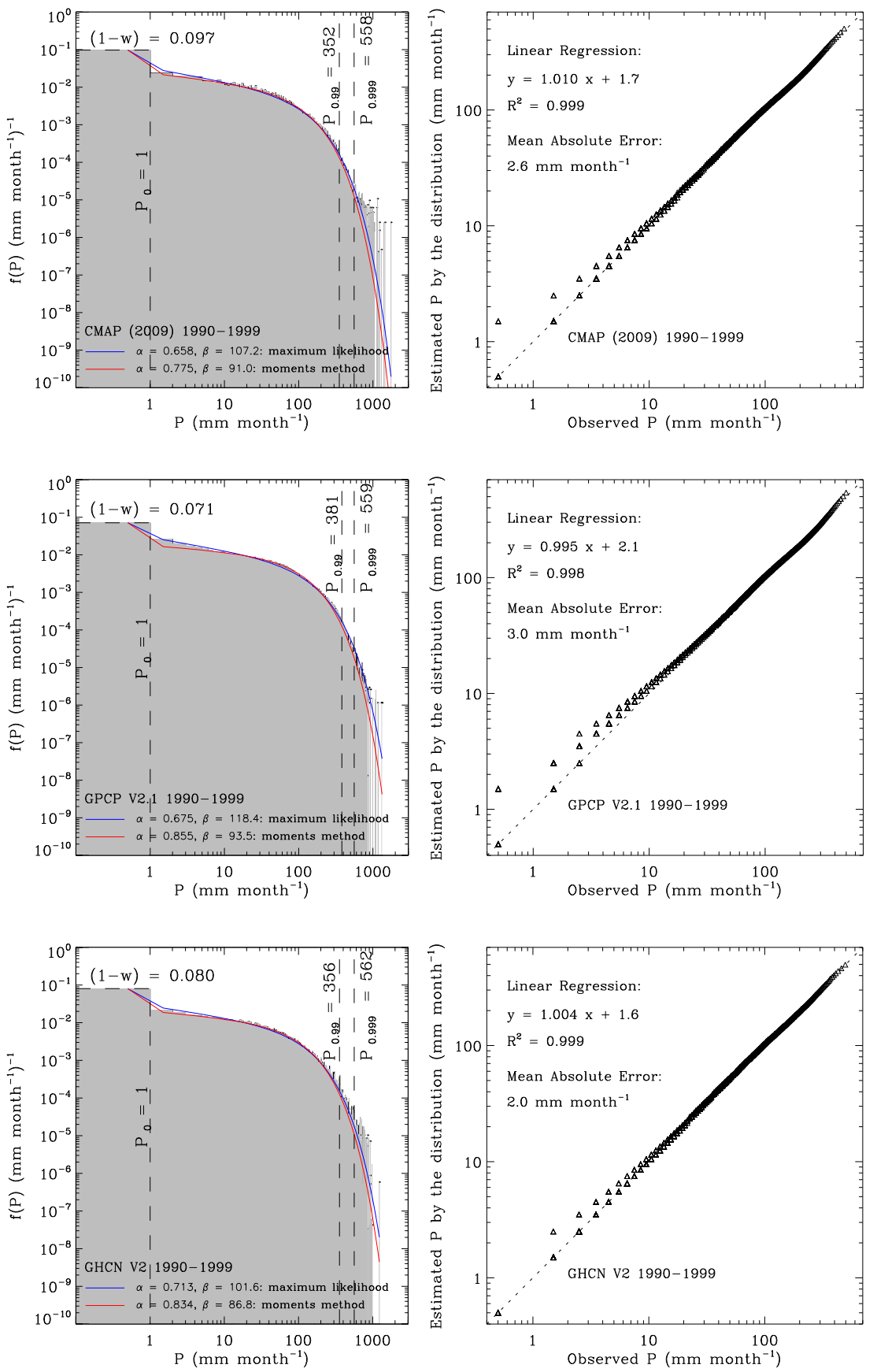

Figure S17 | (Continued). 

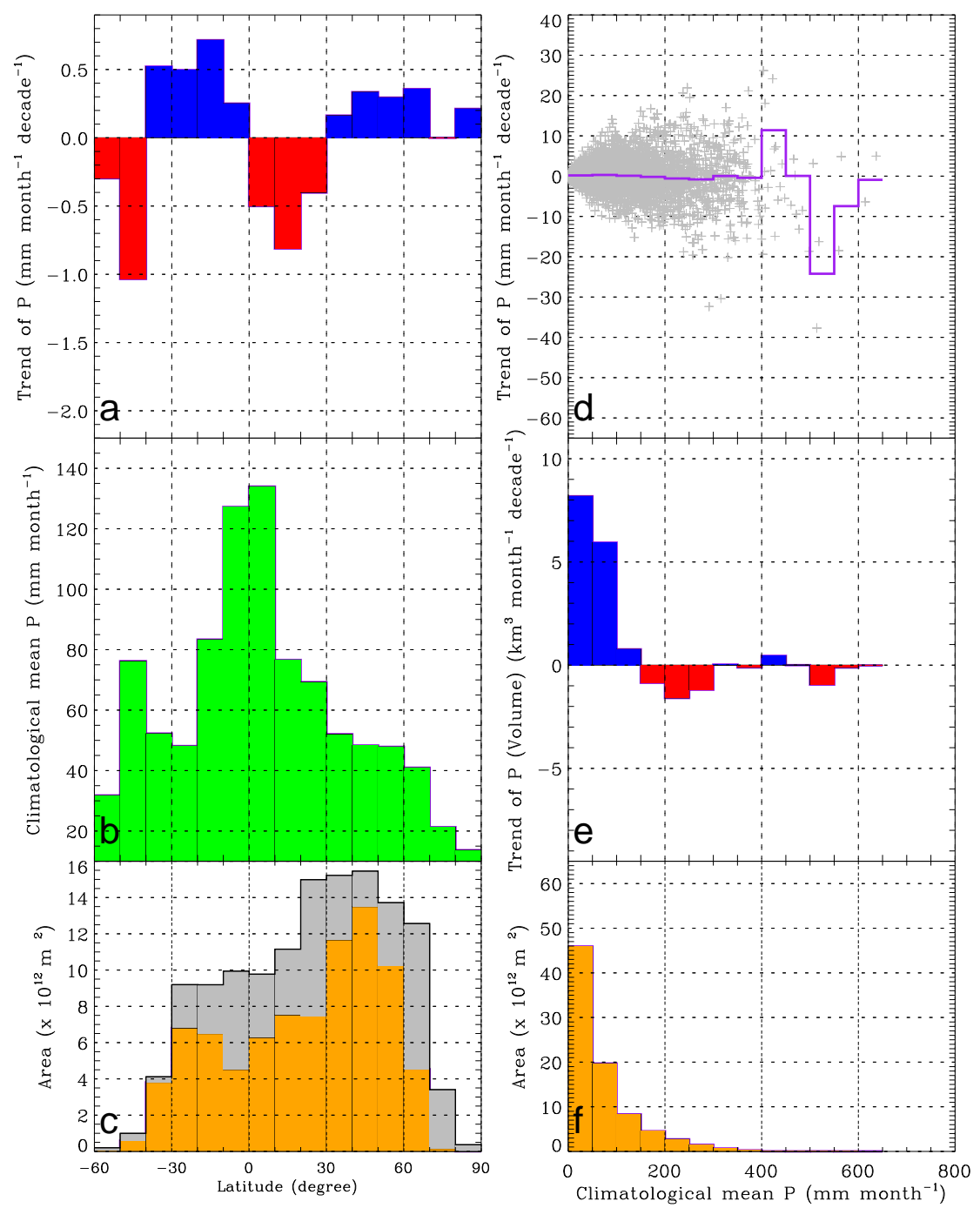

Figure S18 | Analogous to Fig.4 (in the main text) but for the GHCN database (19402009). 

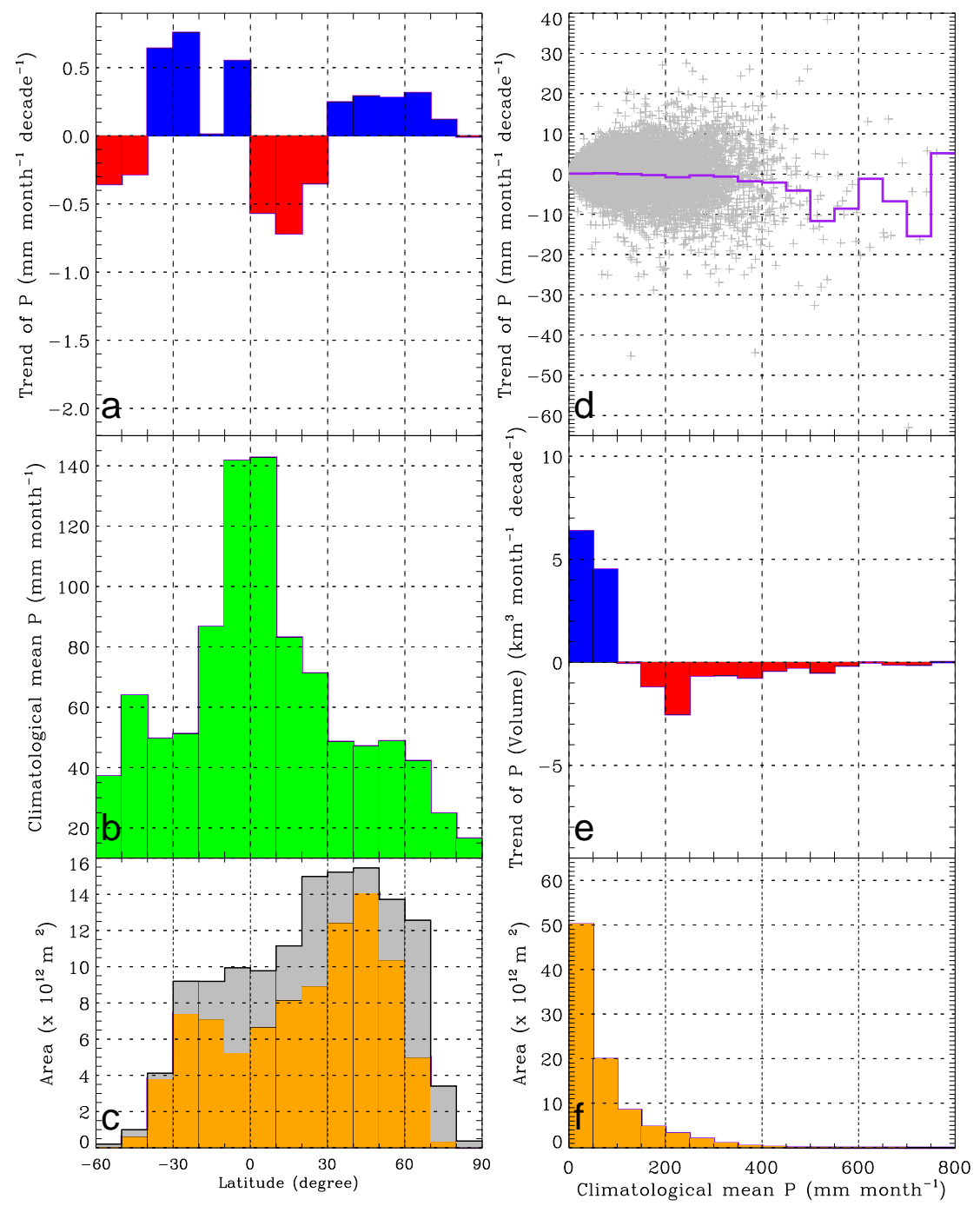

Figure S19 | Analogous to Fig.4 (in the main text) but for the CRU database (19402006). 

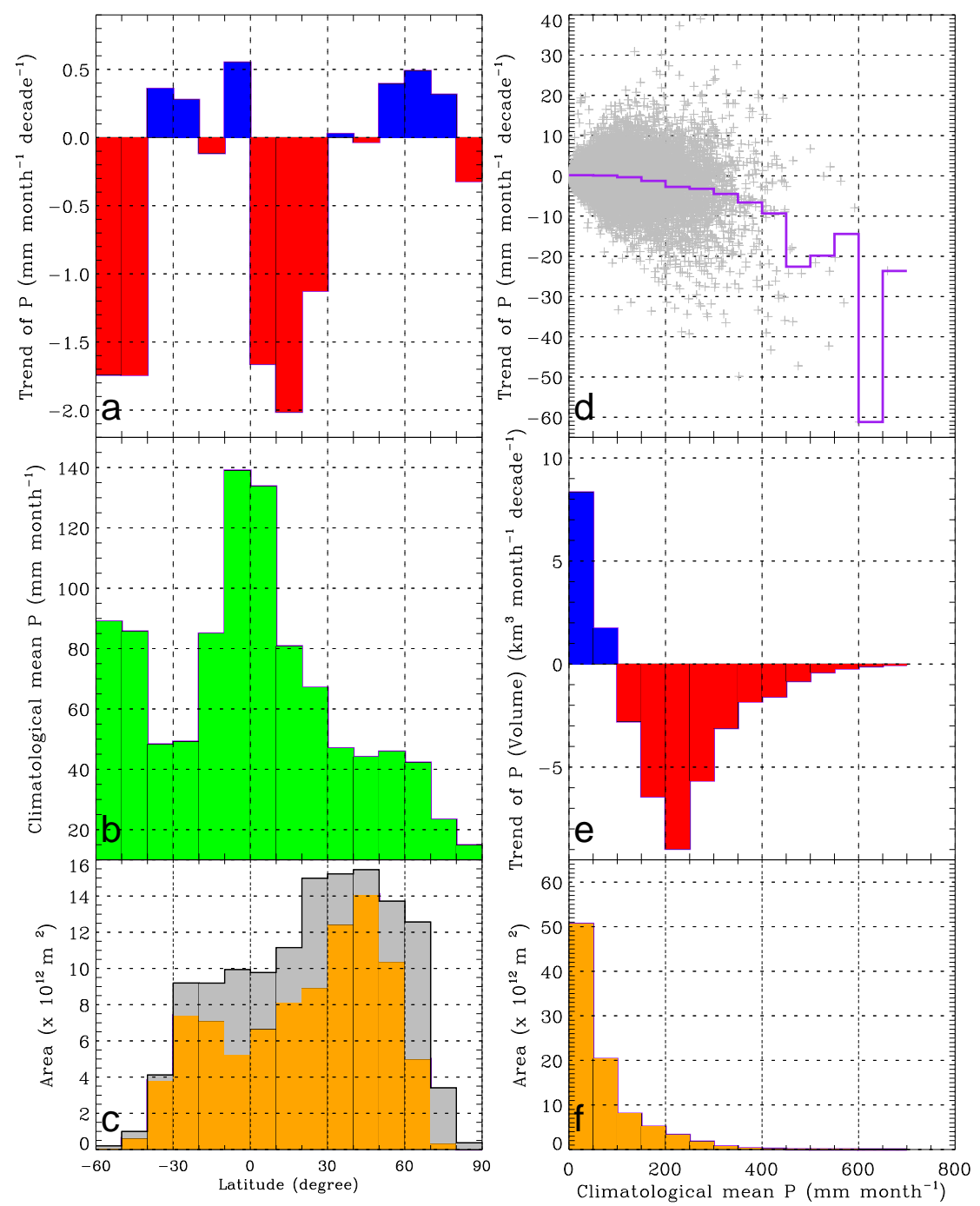

Figure S20 | Analogous to Fig.4 (in the main text) but for the Dai1997 database (19401995). 

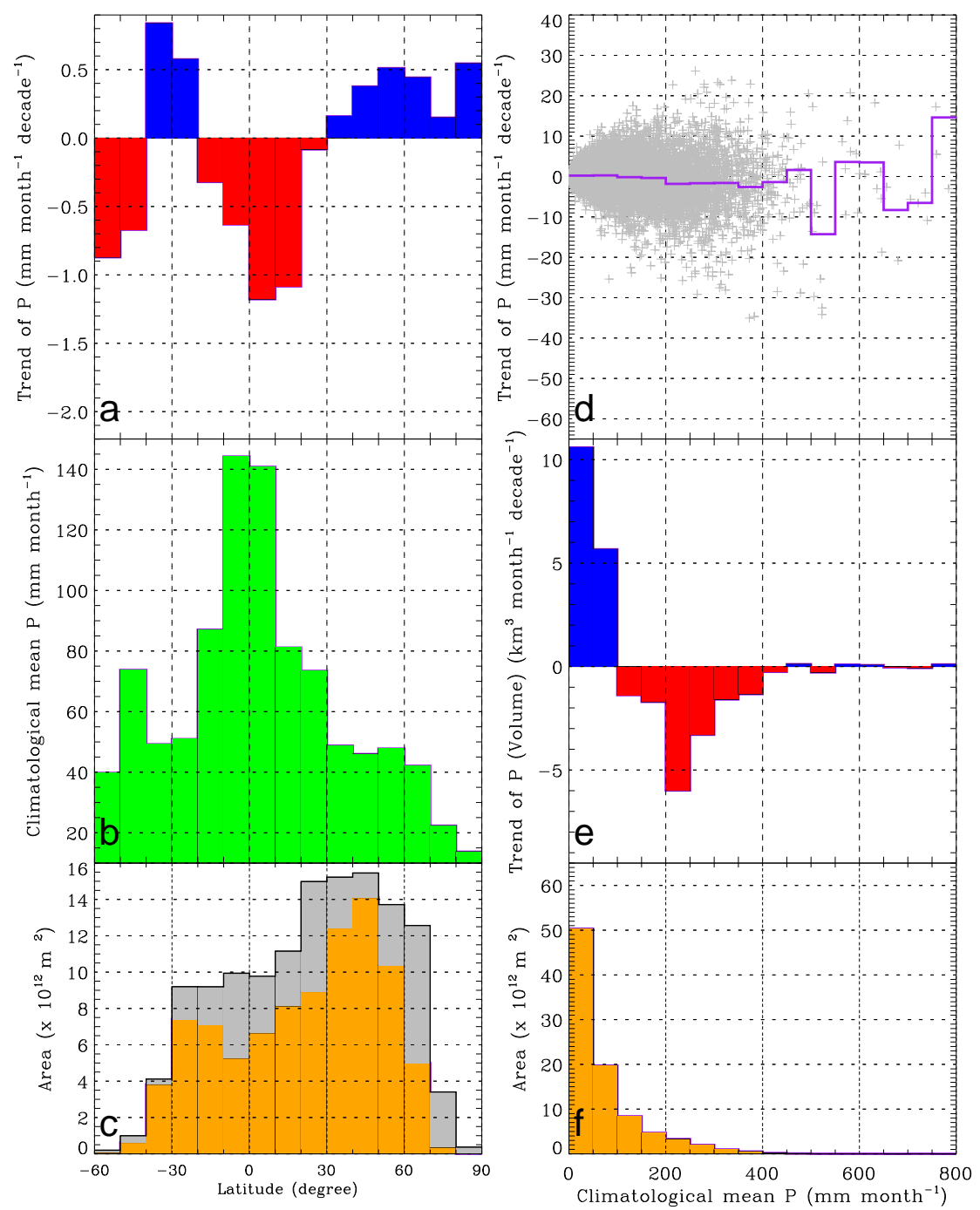

Figure S21 | Analogous to Fig.4 (in the main text) but for the GPCC database (19401999). 

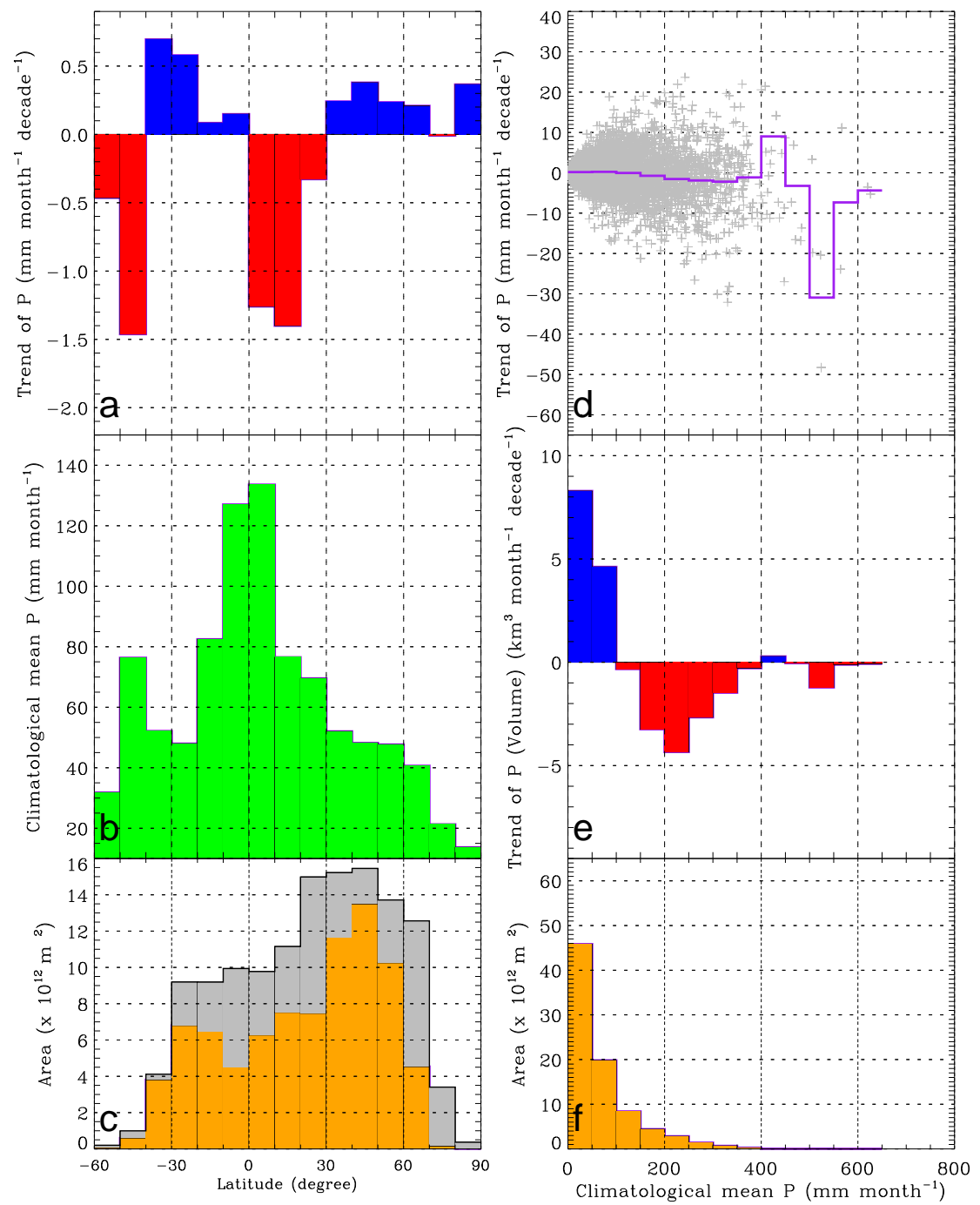

Figure S22 | Analogous to Fig.4 (in the main text) but for the GHCN database (19401999). 

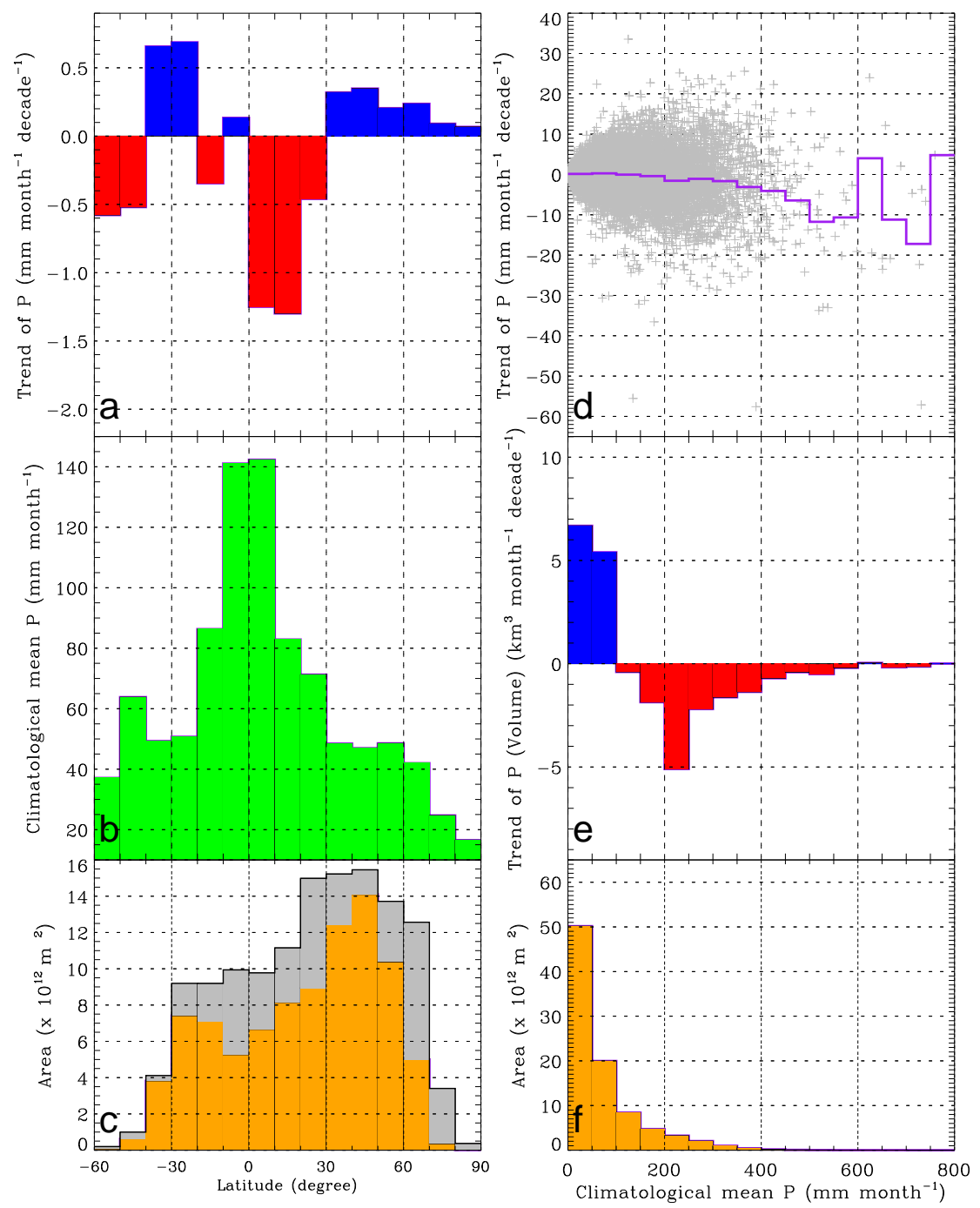

Figure S23 | Analogous to Fig.4 (in the main text) but for the CRU database (19401999). 

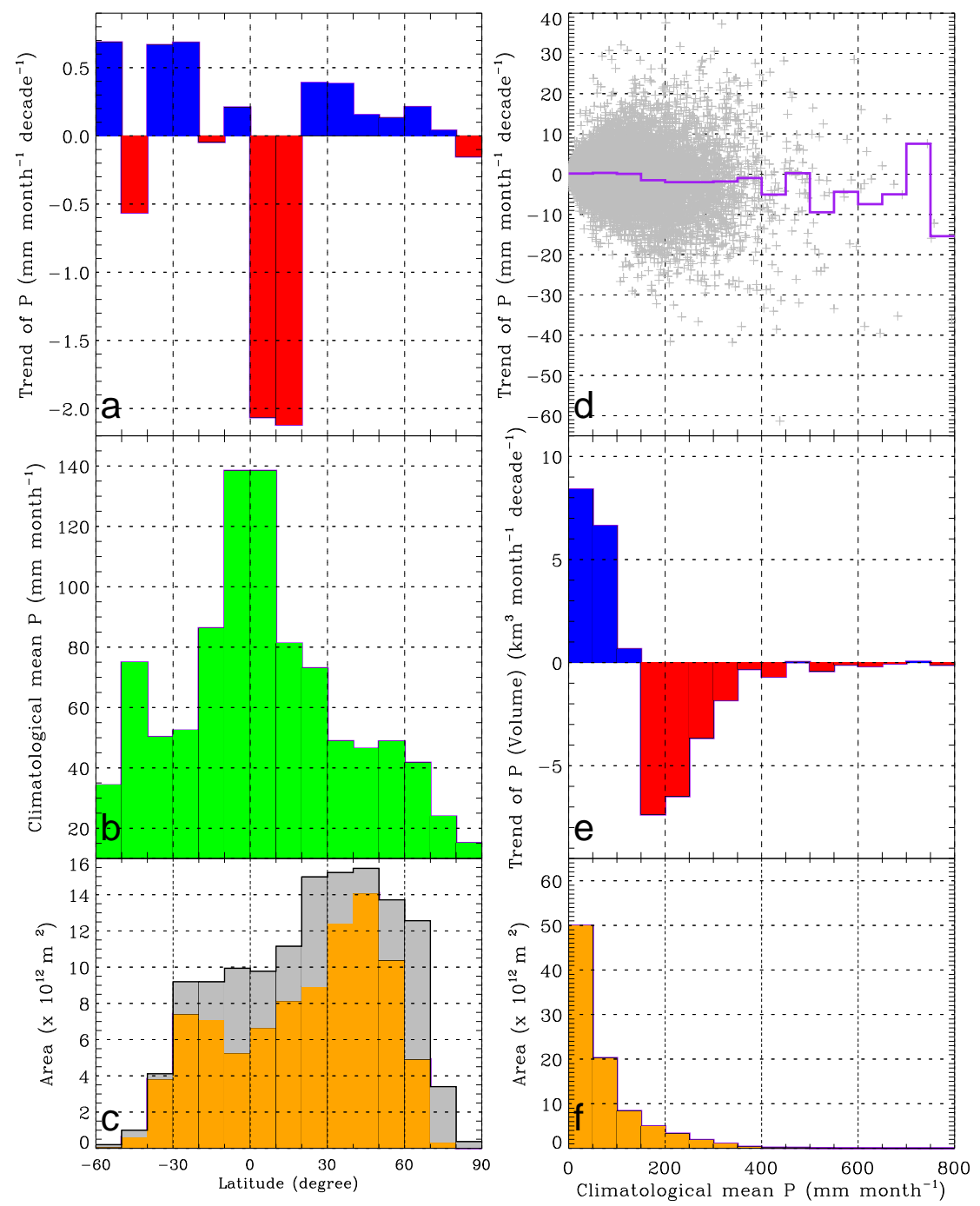

Figure S24 | Analogous to Fig.4 (in the main text) but for the VASClimO database (1951-2000). 


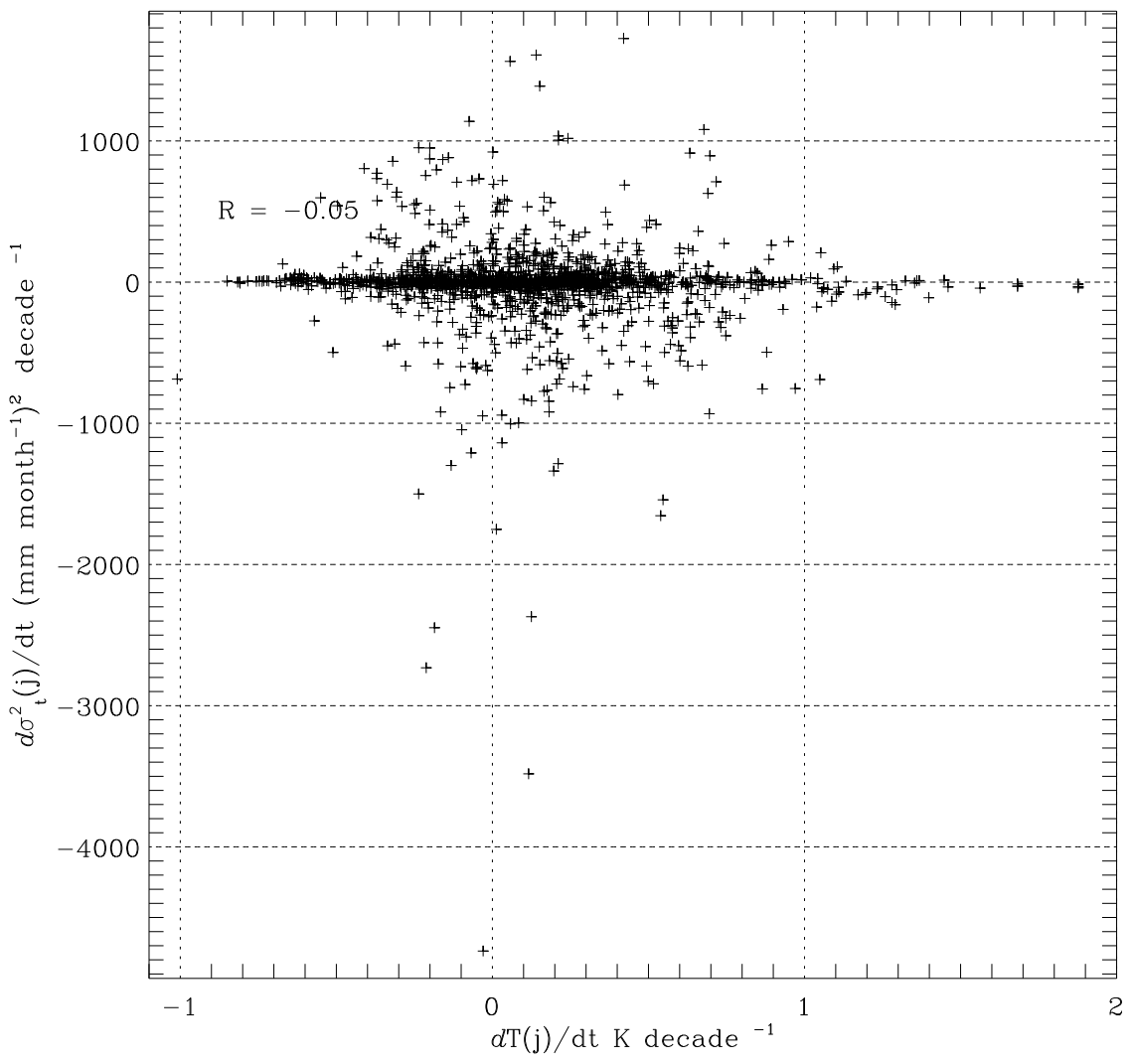

Figure S25 | Relationship between trends in grid-box level near surface air temperature ( $T(j)$, GISS, 1940-2009) and the temporal variance $\left(\sigma_{t}^{2}(j)\right)$ of $P$ (GPCC, 1940-2009). (Linear regression, $R=-0.05)$. 


\section{S4. Supporting Tables}

Table S1. Climatology (1940-2009) of the decadal grand mean, grand variance and the underlying variance components of the monthly GPCC observations. | Units: mm month $^{-1}$ for the mean; and (mm month $\left.{ }^{-1}\right)^{2}$ for the variances. Calculations are based on the decadal block: $m=120$ months ( $q=10$ yrs, $p=12$ months per yr) and $n=1,987$ grid-boxes (Eqns.S1 and S2).

\begin{tabular}{lllllll}
\hline Variable & $\begin{array}{l}\text { Grand } \\
\text { mean }\end{array}$ & $\begin{array}{l}\text { Grand } \\
\text { variance }\end{array}$ & Temporal component & Spatial component \\
\cline { 2 - 6 } & $\mu_{g}$ & $\sigma_{g}^{2}$ & $\frac{n(m-1)}{m \times n-1}$ & $\overline{\sigma_{t}^{2}}$ & $\frac{m(n-1)}{m \times n-1}$ & $\sigma_{s}^{2}(\mu)$ \\
\hline Variable & 68.8 & 7648.3 & 0.99167 & 4667.4 & 0.99950 & 3021.2 \\
& & $\begin{array}{l}\text { Temporal } \\
\text { variance }\end{array}$ & Intra-annual component & Inter-annual component \\
\cline { 2 - 6 } & $\overline{\sigma_{t}^{2}}$ & $\frac{q(p-1)}{p \times q-1}$ & $\overline{\sigma_{a}^{2}}$ & $\frac{p(q-1)}{p \times q-1}$ & $\sigma_{e}^{2}(\mu)$ \\
\hline & & 0.92437 & 4876.8 & 0.90756 & 175.7 \\
\hline
\end{tabular}


Table S2. Trends in the decadal grand mean, grand variance and the underlying variance components in the monthly GPCC observations (1940-2009). | Units: mm month $^{-1}$ decade $^{-1}$ for the trend in the mean; and $\left(\mathrm{mm} \text { month }^{-1}\right)^{2}$ decade $^{-1}$ for the trend in the variances.

\begin{tabular}{lllllll}
\hline Variable & $\begin{array}{l}\text { Grand } \\
\text { mean }\end{array}$ & $\begin{array}{l}\text { Grand } \\
\text { variance }\end{array}$ & Temporal component & Spatial component \\
\cline { 2 - 7 } & $\frac{d \mu_{g}}{d t}$ & $\frac{d \sigma_{g}^{2}}{d t}$ & $\frac{n(m-1)}{m \times n-1}$ & $\frac{d \overline{\sigma_{t}^{2}}}{d t}$ & $\frac{m(n-1)}{m \times n-1}$ & $\frac{d \sigma_{s}^{2}(\mu)}{d t}$ \\
\hline Trend & 0.02 & -34.4 & 0.99167 & -22.8 & 0.99950 & -11.9 \\
\hline \% decade ${ }^{-1}$ & 0.02 & -0.5 & & -0.5 & & -0.4 \\
\hline & & Temporal & Intra-annual component & Inter-annual component \\
\cline { 2 - 7 } & & variance & $\frac{q(p-1)}{p \times q-1}$ & $\frac{d \overline{\sigma_{a}^{2}}}{d t}$ & $\frac{p(q-1)}{p \times q-1}$ & $\frac{d \sigma_{e}^{2}(\mu)}{d t}$ \\
\hline Trend & & -22.8 & 0.92437 & -25.8 & 0.90756 & 1.2 \\
\hline \% decade ${ }^{-1}$ & -0.5 & & -0.5 & & 0.7 \\
\hline
\end{tabular}


Table S3. Analogous to Table S2 but for 1940-1999. | Units: mm month ${ }^{-1}$ decade $^{-1}$ for the mean; and (mm month $\left.{ }^{-1}\right)^{2}$ decade $^{-1}$ for the variance.

\begin{tabular}{|c|c|c|c|c|c|c|}
\hline \multirow[t]{3}{*}{ Variable } & Grand & Grand & \multicolumn{2}{|c|}{ Temporal component } & \multicolumn{2}{|c|}{ Spatial component } \\
\hline & $d \mu_{g}$ & $d \sigma_{g}^{2}$ & $n(m-1)$ & $d \overline{\sigma_{t}^{2}}$ & $m(n-1)$ & $d \sigma_{s}^{2}(\mu)$ \\
\hline & $d t$ & $\overline{d t}$ & $m \times n-1$ & $\overline{d t}$ & $m \times n-1$ & $d t$ \\
\hline Trend & -0.01 & -89.6 & 0.99167 & -57.0 & 0.99950 & -33.1 \\
\hline \multirow[t]{4}{*}{$\%$ decade $^{-1}$} & -0.02 & -1.2 & & -1.2 & & -1.1 \\
\hline & & $\begin{array}{l}\text { Temporal } \\
\text { variance }\end{array}$ & \multicolumn{2}{|c|}{ Intra-annual component } & \multicolumn{2}{|c|}{ Inter-annual componen } \\
\hline & & $d \overline{\sigma_{t}^{2}}$ & $q(p-1)$ & $d \overline{\sigma_{a}^{2}}$ & $p(q-1)$ & $d \sigma_{e}^{2}(\mu)$ \\
\hline & & $\overline{d t}$ & $\overline{p \times q-1}$ & $\overline{d t}$ & $\overline{p \times q-1}$ & $d t$ \\
\hline Trend & & -57.0 & 0.92437 & -61.3 & 0.90756 & -0.4 \\
\hline$\%$ decade $^{-1}$ & & -1.2 & & -1.3 & & -0.2 \\
\hline
\end{tabular}


Table S4. Analogous to Table S2 but for 1980-2009, respectively. | Units: mm month ${ }^{-1}$ decade $^{-1}$ for the mean; and (mm month $\left.{ }^{-1}\right)^{2}$ decade $^{-1}$ for the variance.

\begin{tabular}{lllllll}
\hline Variable & $\begin{array}{l}\text { Grand } \\
\text { mean }\end{array}$ & $\begin{array}{l}\text { Grand } \\
\text { variance }\end{array}$ & Temporal component & Spatial component \\
\cline { 2 - 7 } & $\frac{d \mu_{g}}{d t}$ & $\frac{d \sigma_{g}^{2}}{d t}$ & $\frac{n(m-1)}{m \times n-1}$ & $\frac{d \overline{\sigma_{t}^{2}}}{d t}$ & $\frac{m(n-1)}{m \times n-1}$ & $\frac{d \sigma_{s}^{2}(\mu)}{d t}$ \\
\hline Trend & 0.3 & 178.1 & 0.99167 & 126.6 & 0.99950 & 52.6 \\
\hline \% decade ${ }^{-1}$ & 0.5 & 2.3 & & & & 1.7 \\
\hline & & Temporal & Intra-annual component & Inter-annual component \\
\cline { 2 - 7 } & & $\frac{d \overline{\sigma_{t}^{2}}}{d t}$ & $\frac{q(p-1)}{p \times q-1}$ & $\frac{d \overline{\sigma_{a}^{2}}}{d t}$ & $\frac{p(q-1)}{p \times q-1}$ & $\frac{d \sigma_{e}^{2}(\mu)}{d t}$ \\
\hline Trend & 126.6 & 0.92437 & 129.8 & 0.90756 & 7.4 \\
\hline \% decade ${ }^{-1}$ & 2.7 & & 2.7 & & 4.2 \\
\hline
\end{tabular}

